\title{
GSE4 peptide suppresses oxidative and telomere deficiencies in ataxia telangiectasia patient cells
}

\author{
Laura Pintado-Berninches ${ }^{1,2}$ - Beatriz Fernandez-Varas ${ }^{1} \cdot$ Carlos Benitez-Buelga $^{3}$ - Cristina Manguan-Garcia ${ }^{1,4}$. \\ Almudena Serrano-Benitez ${ }^{5}$ - Laura larriccio ${ }^{1,2}$ - Jaime Carrillo ${ }^{1}$ - Guillermo Guenechea ${ }^{4,6,7}$. \\ Susana P. Egusquiaguirre ${ }^{8,9} \cdot$ Jose-Luis Pedraz ${ }^{8,9} \cdot$ Rosa M. Hernández $^{8,9} \cdot$ Manoli Igartua $^{8,9}$. \\ Elena G. Arias-Salgado ${ }^{1,2} \cdot$ Felipe Cortés-Ledesma ${ }^{5} \cdot$ Leandro Sastre $^{1,4} \cdot$ Rosario Perona (D) ${ }^{1,4}$
}

Received: 3 February 2018 / Revised: 21 November 2018 / Accepted: 3 December 2018 / Published online: 22 January 2019

(c) ADMC Associazione Differenziamento e Morte Cellulare 2019

\begin{abstract}
Ataxia telangiectasia (AT) is a genetic disease caused by mutations in the ATM gene but the mechanisms underlying AT are not completely understood. Key functions of the ATM protein are to sense and regulate cellular redox status and to transduce DNA double-strand break signals to downstream effectors. ATM-deficient cells show increased ROS accumulation, activation of p38 protein kinase, and increased levels of DNA damage. GSE24.2 peptide and a short derivative GSE4 peptide corresponding to an internal domain of Dyskerin have proved to induce telomerase activity, decrease oxidative stress, and protect from DNA damage in dyskeratosis congenita (DC) cells. We have found that expression of GSE24.2 and GSE4 in human AT fibroblast is able to decrease DNA damage, detected by $\gamma$-H2A.X and 53BP1 foci. However, GSE24.2/GSE4 expression does not improve doublestrand break signaling and repair caused by the lack of ATM activity. In contrast, they cause a decrease in 8-oxoguanine and OGG1-derived lesions, particularly at telomeres and mitochondrial DNA, as well as in reactive oxygen species, in parallel with increased expression of SOD1. These cells also showed lower levels of IL6 and decreased p38 phosphorylation, decreased senescence and increased ability to divide for longer times. Additionally, these cells are more resistant to treatment with $\mathrm{H}_{2} \mathrm{O}_{2}$ and the radiomimetic-drug bleomycin. Finally, we found shorter telomere length (TL) in AT cells, lower levels of TERT expression, and telomerase activity that were also partially reverted by GSE4. These observations suggest that GSE4 may be considered as a new therapy for the treatment of AT that counteracts the cellular effects of high ROS levels generated in AT cells and in addition increases telomerase activity contributing to increased cell proliferation.
\end{abstract}

These authors contributed equally: Leandro Sastre, Rosario Perona

Edited by P. Salomoni

Supplementary information The online version of this article (https:// doi.org/10.1038/s41418-018-0272-7) contains supplementary material, which is available to authorized users.

Rosario Perona

RPerona@iib.uam.es

1 Instituto de Investigaciones Biomédicas CSIC/UAM, IDiPaz, C/ Arturo Duperier, 4, 28029 Madrid, Spain

2 Advanced Medical Projects, Madrid, Spain

3 National Center for Cancer Research, CNIO, Madrid, Spain

4 CIBER de Enfermedades Raras, Madrid, Spain

5 Centro Andaluz de Biologia Molecular y Medicina regenerativa (CABIMER) - CSIC, Universidad de Sevilla, Universidad Pablo de Olavide, Sevilla, Spain

\section{Introduction}

Ataxia telangiectasia (AT) is a rare autosomal syndrome due to inactivation of ATM (AT-mutated) a Ser/Thr protein kinase from the PIKK family $[1,2]$. AT is characterized by progressive cerebellar ataxia, immunodeficiency, radiosensitivity,

6 Division of Hematopoietic Innovative Therapies, Centro de Investigaciones Energéticas, Medioambientales y Tecnológicas (CIEMAT), Madrid, Spain

7 Advanced Therapies Unit, Instituto de Investigación Sanitaria Fundación Jiménez Díaz (IIS-FJD), Madrid, Spain

8 NanoBioCel Group, Laboratory of Pharmaceutics, University of the Basque Country, School of Pharmacy, Vitoria-Gasteiz, Spain

9 Biomedical Research Networking Center in Bioengineering, Biomaterials and Nanomedicine (CIBER-BBN), VitoriaGasteiz, Spain 
and increased cancer incidence. Functions assigned to ATM include, cell cycle regulation, DNA repair, and cellular redox status [3]. The best understood function of ATM is the initial phosphorylation of the DNA double-strand breaks (DSBs) damage response pathway. Accordingly, AT patients and deficient cells display increased radiosensitivity, strongly suggesting a link between DSBs sensitivity and this pathology $[2,3]$. ATM is involved in efficient and accurate DSB repair, preventing cell death and genomic instability exclusively when DNA ends are irreversibly blocked. Therefore, blocked DNA ends may be the pathogenic trigger of AT [4]. After DSB, ATM is rapidly recruited to DNA damage sites [5], and dissociates from homodimers into active monomers [6] by autophosphorylation. ATM phosphorylates multiple substrates [3] involved in recognition of DSBs in DNA and in cell cycle checkpoint activation among other functions [7]. Key events in this initial ATM-mediated DNA damage response (DDR) are phosphorylation of histone variant $\mathrm{H} 2 \mathrm{~A}$. $X$ in Ser139 $(\gamma-H 2 A . X)$ in the chromatin surrounding the DSB, and recruitment of 53BP1. Both events can be cytologically visualized by their accumulation in nuclear foci, and are widely used for the quantification of DSBs.

Another key ATM function is to sense and regulate cellular redox. In ATM deficiency, cellular redox homeostasis is severely disrupted resulting in high levels of reactive oxygen species (ROS), which may contribute to the progressive neurodegeneration displayed by AT patients [8]. In response to oxidative stress (OS), p38 mitogen-active protein kinase (p38) is activated in ATM-depleted cells [9] and treatment with the specific p38 inhibitor SB203580 restores normal proliferation. Persistent DNA damage leads AT cells to permanent mitotic arrest or senescence [10]. Several inflammatory cytokines, such as interleukin-6 (IL6) and IL-8, are secreted by these senescent cells and enforce senescence [11] allowing damaged cells to communicate their compromised state to the surrounding tissue. Therefore, damaged cells can contribute to tissue dysfunction promoting inflammation, angiogenesis, or other inducers of cancer progression [12].

GSE24.2 is a peptide corresponding to an internal domain of dyskerin [13]. Dyskerin mutations cause the rare disease X-linked dyskeratosis congenita (X-DC) [14]. Individuals with X-DC show premature ageing, bone marrow failure, pulmonary fibrosis, and increased susceptibility to cancer [15, 16]. GSE24.2 expression increases telomerase reverse transcriptase (TERT) mRNA and TERC levels and the recovery of telomerase activity [13-18]. Expression of GSE24.2 and GSE4 (composed by the 11 N-terminal amino acids of GSE24.2) reduce DNA damage in X-DC cell lines, decreasing $\mathrm{OS}$ and increasing expression of detoxifying genes. This results in decreased cell senescence and increased proliferation [19]. Due to GSE24.2 and GSE4 properties, we aimed to test their function in AT cells. Expression of both peptides reduced basal levels of DNA damage in AT cells probably due to reduced oxidative DNA damage, and not to increased DSB repair capacity. Further, AT cells expressing both peptides were able to divide for longer periods of time and showed reduced acid- $\beta$ galactosidase activity as a senescence marker, expression of IL6, increased expression of TERT and telomerase activity, elongation of telomeres, and decreased oxidation of telomere and mitochondrial DNA. Altogether our results support a potential therapeutic role of GSE24.2/GSE4 in AT cells mainly by decreasing OS and increasing telomerase activity with positive effects on cell growth.

\section{Results}

\section{Expression of GSE24.2 and GSE4 in AT cells decreases spontaneous DNA damage signaling}

The effect of GS24.4/GSE4 on DDR, was studied in human fibroblast cell lines from AT patients GMO3487 (AT-3487) and controls GMO1787 (C-1787, C-3490), measuring $\gamma$-H2A. $\mathrm{X}$ accumulation. AT fibroblasts rapidly senesce in vitro, therefore we also used AT (AT-3189, AT-719, AT-137IIB) and control lymphoblast cell lines (C-736, C-JY). We generated stable cell lines by transduction of GSE24.2 (LV-CMV-GSE24.2-eGFP), GSE4 (LV-CMV-GSE4-eGFP), control vectors (LV-CMV-eGFP), and GSE-scramble (LV-CMV-scramble-eGFP). Expression levels of GSE4 and GSE24.2 in transduced cells are presented in Fig S1. We first studied fibroblast and found that the number of $\gamma$-H2A.X foci/ cell was higher in AT-3487 than in control C-1787 and C-3490 cells (Fig. 1a and Fig S2). Damage was partially reverted in AT-3487 cells expressing GSE24.2 and GSE4. AT-3487-GSE24.2 and AT-3487-GSE4 cells showed increased number of cells with low signal (0-4) $\gamma$-H2A.Xassociated foci. We also investigated the presence of 53BP1 foci, more specific than $\gamma$-H2A.X for DSBs. The average number of foci/cell was similar to that observed for $\gamma-\mathrm{H} 2 \mathrm{AX}$, higher in AT-3487 than in control C-1787 and C-3490 cells, and also decreased in AT-3487-GSE24.2 and AT-3487-GSE4 cells (Fig. 1a and Fig S3). Finally, we treated AT-3487 cells with empty, GSE24.2 or GSE4-PLGA-PEI nanoparticles [20] and evaluated the number of $\boldsymbol{\gamma}$-H2A.X-associated foci/cell (Fig. 1b). GSE24.2 and GSE4 loaded nanoparticles reduced the $\gamma$-H2A.X signal obtained, strongly suggesting that both peptides have similar effects in AT cells. Similar results were obtained determining $\gamma-\mathrm{H} 2 \mathrm{AX}$ levels by western blot in C-736 and C-JY control cells in comparison with AT-719, AT-3189, and AT-L137IIB cells or those expressing GSE24.2 or GSE4 (Fig. 1c). 
a
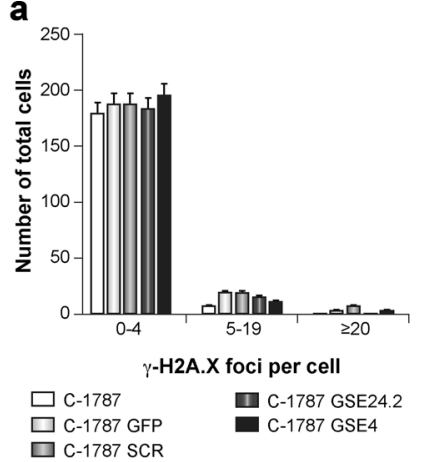

$\square \mathrm{C}-1787$ SCR
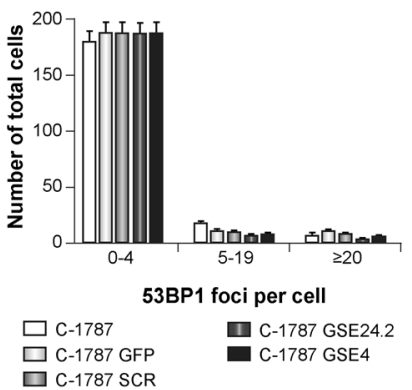

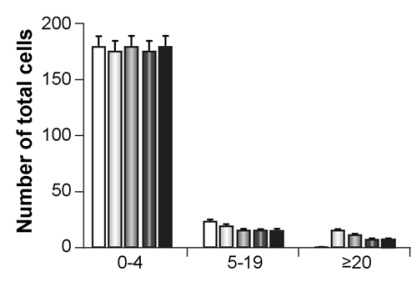

$\gamma-\mathrm{H} 2 \mathrm{~A} . \mathrm{X}$ foci per cell
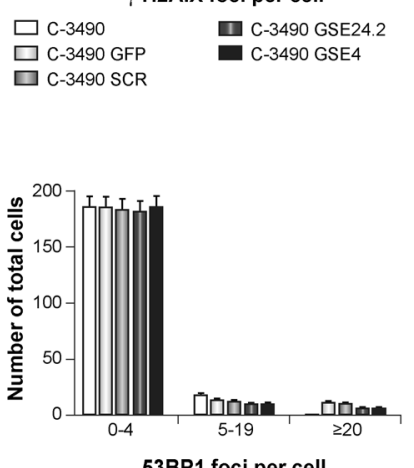

53BP1 foci per cell

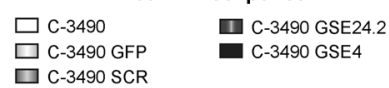

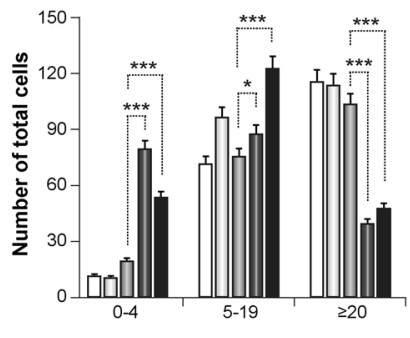

$\gamma$-H2A.X foci per cell
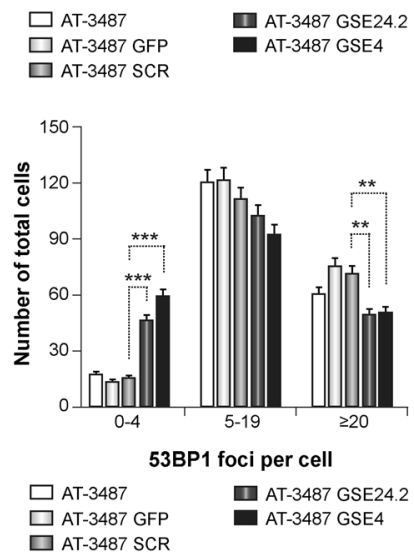

b
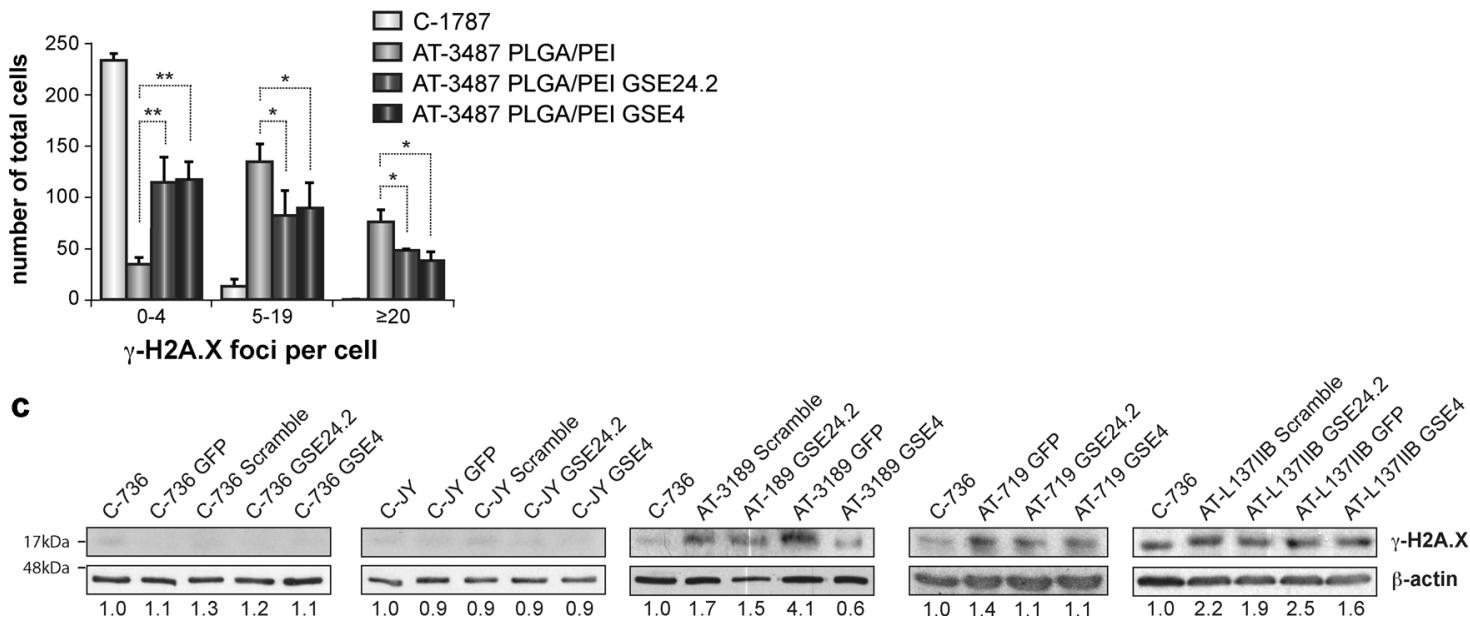

Fig. 1 DNA damage in ataxia telangiectasia (AT) cells after expression of GSE24.2 or GSE4. a Quantification of $\gamma-\mathrm{H} 2 \mathrm{AX}$ - and 53BP1associated foci in C-1787, C-3490 and AT patient AT-3487 cells expressing either GFP, scramble, GSE24.2, or GSE4. More than 200 cells were analyzed in each cell line. Results are indicated as the average number of foci/cell that was divided into three groups and the number of cells in each group indicated. Average values and standard deviations of two independent experiments are shown. Asterisks indicate significant differences between cell lines. b DNA damage in AT cells after treatment with nanoparticles loaded with GSE24.2 or GSE4. Control C-1787 untreated and AT-3487 cells incubated with empty PLGA/PEI, or PLGA/PEI nanoparticles loaded with the equivalent of $15 \mu \mathrm{g}$ peptide/ $2 \mathrm{~mL}$ of GSE24.2 or GSE4 were treated during $24 \mathrm{~h}$, fixed and incubated with antibodies against $\gamma-\mathrm{H} 2 \mathrm{AX}$ and secondary fluorescent antibodies. Nuclear DNA was counterstained with DAPI. More than 200 cells were analyzed in each cell line and indicated as the average number of foci/cell. Average values and standard deviations of two independent experiments are shown. Asterisks indicate significant differences in relation to control cell lines. c C-736 and C-JY control lymphoblasts or AT-719, AT-3189, or AT-L137IIB transduced with lentiviral vectors expressing scramble, GFP, GSE24.2, or GSE4 were used for obtaining protein extracts and analyzed by western blotting. The membranes were blotted with $\gamma-\mathrm{H} 2 \mathrm{AX}$ antibody and to $\beta$-actin as control. The membranes were processed to quantify the relative expression of $\gamma$-H2AX to $\beta$-actin and the ratio indicated for each gel lane 
Expression of GSE24.2 or GSE4 reduces oxidative damage caused by ATM loss but does not affect DSB signaling and repair deficiencies

Accumulation of $\gamma$-H2A.X can be influenced by three factors: (i) the level of endogenous DNA damage, (ii) the signaling of this damage, and (iii) the rate of repair. DDR activation was analyzed determining $\gamma$-H2A.X foci formation induced by the chemotherapeutic agent etoposide, which generates DSBs by impairing the activity of DNA topoisomerase II (TOP2) [21]. These breaks present covalent binding of TOP2-derived peptides to $5^{\prime}$-DNA ends, which, in the absence of the enzyme TDP2 results in irreversible blockage, requiring nucleolytic activity for repair through a pathway that specifically requires ATM function [4]. As previously described, etoposide treatment induced $\gamma$-H2A.X foci formation in $T d p 2^{-/-}$mouse embryonic fibroblasts (MEFs), which were smaller and less bright upon treatment with ATM inhibitor (ATMi) (Fig. 2a). This effect was independent of GSE24.2 (Fig. 2a) or GSE4 (data not shown) expression, indicating that these peptides do not affect DDR signaling in response to DSBs. Finally, to analyze DSB repair, we monitored the disappearance of etoposide-induced $\gamma$-H2A.X foci in $T d p 2^{-/-}$MEFs (Fig. 2b), highly depends on ATM function. DSB repair was not improved (if something slightly impaired) by expression of either GSE24.2 or GSE4, with $>10 \gamma$-H2A.X foci/cell remaining after $6 \mathrm{~h}$ of repair. Overall, we conclude that the effect of GSE24.2/GSE4 on the spontaneous accumulation of $\gamma$-H2A.X in AT cells is unlikely related to modulation of DDR signaling or DSB repair. We also used human control cell lines C-1787 and C-3490 expressing either GFP or GSE4 in a similar experiment, treating the cells with bleomycin and ATMi (Fig. 2c). We observed that damage increased at $6 \mathrm{~h}$ and remained to the same level at $24 \mathrm{~h}$ in the absence of ATMi, with a small decrease in those expressing GSE4. But in the presence of ATMi, there was an increase in $\gamma$-H2A.X foci/cell at $24 \mathrm{~h}$. This difference should be due to DDR signaling in response to DSBs, not repaired by GSE4.

We next studied if the decrease in DNA damage may be due to decreased spontaneous oxidative DNA damage investigating if GSE4 was able to reduce this damage in AT cells [8]. We treated AT-3487 cells with PLGA-PEIGSE4-nanoparticles and evaluated the levels of 8-oxoguanine by immunofluorescence (Fig. 2d) finding that GSE4 treatment was able to reduce the signal. This finding strongly suggests that GSE4-mediated rescue of DDR activation in AT cells corresponds, at least in part, to an inhibition of DNA oxidative damage.

Increased ROS is a hallmark of AT cells responsible for the reduced repopulation capacity of $\mathrm{ATM}^{-/-}$hematopoietic stem cells (HSCs) [22, 23]. Therefore, we compared
ROS levels in AT cells (AT-3189) expressing GSE24.2 or GSE4 with C-736 control cells. ROS levels were elevated in AT-3189 cells (Fig. 3a) and decreased upon GSE24.2 or GSE4 expression. We previously described that GSE24.2 or GSE4 increased the expression of three antioxidant enzyme genes, SOD1, SOD2 and catalase in DC cells $[18,19]$. Expression of SOD1 and catalase, but not SOD2 were reduced in three AT patient cell lines (Fig. 3b) in comparison with C-736 and C-JY cells. Expression of GSE24.2 and GSE4 in AT-719, AT-L137IIB, or AT-3189 cells increased the mRNA levels of these genes, specially SOD1 (Fig. 3b), suggesting that SOD1 may be involved in the reduction in ROS levels. However, expression of GSE4 in control C-736 or C-JY cells did not induce significant changes in the expression of those genes. SOD1 protein levels also increased in AT-719 cells expressing GSE24.2 or GSE4 (Fig S4a). GSE4 induced the expression of SOD1 in AT cells by stimulating its promoter revealing the mechanism of SOD1 activation (Fig. 4a). To further understand the role of SOD1, we transduced C-736 and AT3189 cells with an shRNA targeting SOD1 (Fig S4b) and measured ROS levels. The results clearly indicated an increase in ROS levels in these cell lines after SOD1 depletion but this increase was higher in AT-3189 cells expressing GSE4 (Fig. 4b and. Fig S4c). We also tested the effect of GSE4 on cell viability after treating control and AT cells with $\mathrm{H}_{2} \mathrm{O}_{2}$ during $72 \mathrm{~h}$. The results indicated increased viability of GSE4-expressing cells, although in C-JY cells the effect was lower (Fig. 4c). Altogether the results indicated that expression of GSE peptides by inducing expression of SOD1 should increase survival to the high ROS levels present in AT cells.

\section{Inhibition of IL-6 expression, p38 phosphorylation, and increased viability by GSE24.2 and GSE4 in AT cells}

Human cells harboring increased persistent chromatin lesions as AT cells secrete inflammatory cytokines such as IL-6 [11]. Given the previous results, we studied the expression of IL-6 and found that was increased in the AT cell lines and diminished upon GSE24.2 or GSE4 expression (Fig. 4d).

Increased levels of ROS in AT cells induce p38 mitogen activated protein (MAP) kinase activation and cell death $[24,25]$. Basal levels of phosphorylated p38 MAP kinase were higher in AT cells AT-719, AT-L137IIB, AT-3189, and AT-3487 than in control cells C-736, C-JY, and C3490 , and decreased after expression of GSE24.2 or GSE4 in AT cells (Fig. 5a). These results support that AT cells expressing GSE24.2 or GSE4 show an important reduction of the pro-apoptotic pathway mediated by activated p38.

ATM deficiency contributes to in vivo senescence in the hematopoietic system [23] probably as a result of persistent 
a

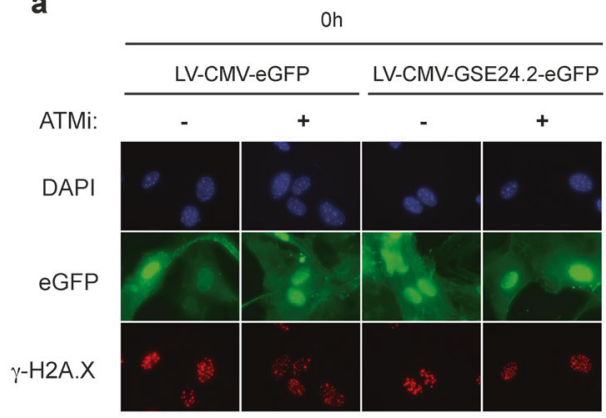

b

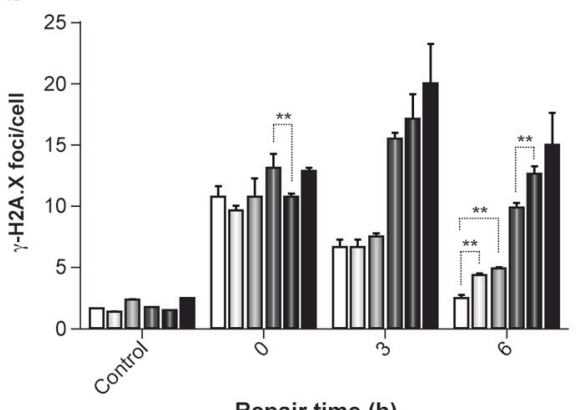

Repair time (h)

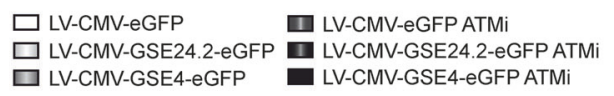

d

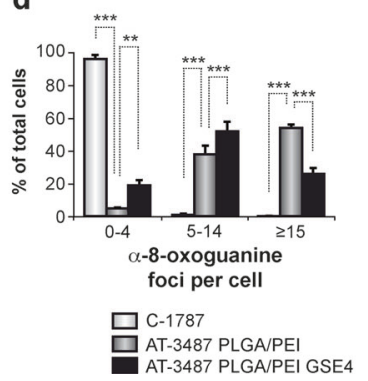

Fig. 2 Expression of GSE24.2 and GSE4 reduced oxidative damage caused by ATM loss but did not affect double-strand break signaling and repair deficiencies. a Representative images of $\gamma$-H2AX foci (red), DAPI counterstain (blue), and eGFP expression (green), in confluence arrested $T d p 2^{-/}$primary mouse embryonic fibroblasts (MEFs) transduced with indicated lentiviral vectors, treated with $10 \mu \mathrm{M}$ etoposide for $30 \mathrm{~min}(0 \mathrm{~h})$ and $3 \mathrm{~h}$ after drug removal. Cells were treated or not with $10 \mu \mathrm{M}$ ATM inhibitor (ATMi) when indicated (3h) bar scale $0.25 \mu \mathrm{m}$ is indicated. b Quantification of the number of $\gamma-\mathrm{H} 2 \mathrm{AX}$ foci in untreated cells at the indicated times after etoposide removal in $T d p 2^{-/}$primary MEFs transduced with indicated lentiviral vectors, $30 \mathrm{~min}(0 \mathrm{~h})$ and 3 and $6 \mathrm{~h}$ after drug removal and treated or not with $10 \mu \mathrm{M}$ ATMi. Experiment was performed in triplicates and repeated twice. c Quantification of the number of $\gamma-\mathrm{H} 2 \mathrm{AX}$ foci in $\mathrm{C}-1787$ and C-3490 cells treated 30 min with bleomycin $(1 \mu \mathrm{M})$ in the presence or

DNA damage. AT-3487 fibroblasts expressing GSE24.2 or GSE4, showed a marked reduction in the expression of the senescence-associated $\beta$-galactosidase (SA- $\beta$-gal), more evident after 8 days of peptide expression (Fig. 5b). Since AT
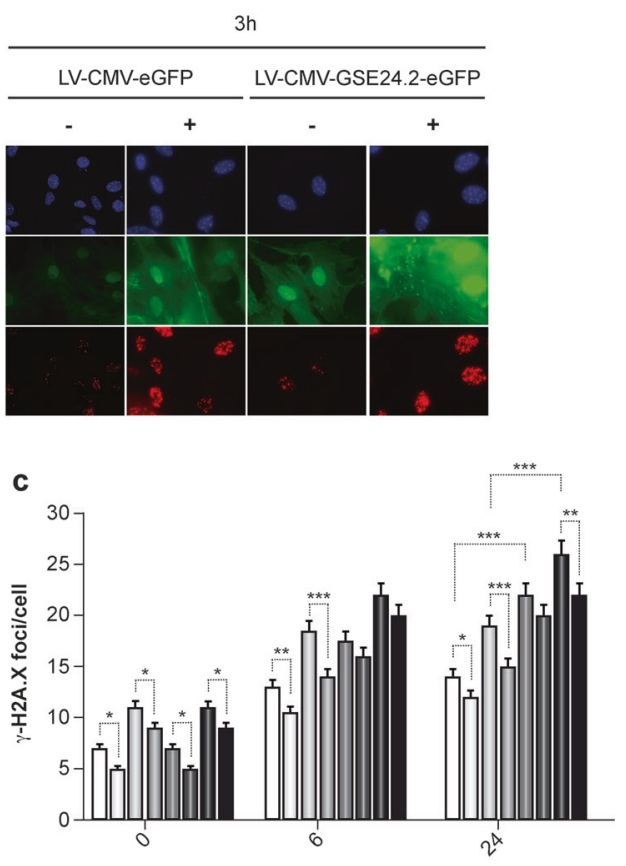

Repair time (h)

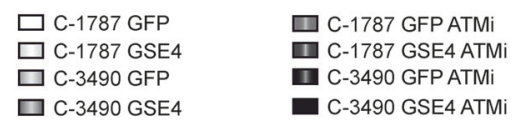

absence of $10 \mu \mathrm{M}$ ATMi. ATMi was maintained at 6 and $24 \mathrm{~h}$ after washing the bleomycin. Repair analysis was carried out, by monitoring the time course of $\gamma-\mathrm{H} 2 \mathrm{AX}$ foci persistence following bleomycin removal. Experiment was performed in triplicates and repeated twice. d 8-oxoguanine levels in control (C-1787) and AT-3487 cells after treatment with PLGA/PEI nanoparticles loaded with GSE4. Control C1787 untreated and AT-3487 cells treated with empty PLGA/PEI, or PLGA/PEI nanoparticles loaded with GSE4 were treated during $24 \mathrm{~h}$, fixed and incubated with antibodies against 8-oxoguanine and secondary fluorescent antibodies. Nuclear DNA was counterstained with DAPI. More than 200 cells were analyzed in each cell line and indicated as the average number of foci/cell. Average values and standard deviations of two independent experiments are shown. Asterisks indicate significant differences between cell lines

fibroblasts grow very poorly in vitro, control and AT lymphoblasts expressing enhanced green fluorescent protein (eGFP), GSE24.2, or GSE4 were allowed to grow along 2 months and the number of accumulated cells expressing 
Fig. 3 ROS levels and expression of antioxidant genes in ataxia telangiectasia (AT) cells expressing GSE24.2 or GSE4. a Control (C-736) and AT-3189 lymphoblasts expressing GFP, GSE24.2, or GSE4 were used to determine the percentage of cells with high intensity with DHE and represented together with the flow cytometry image. The experiments were performed in triplicates and repeated three times with similar results. b Expression levels of antioxidant genes in AT-719, AT-L137IIB, and AT-3189 cells expressing GFP or GSE24.2 and C-736, CAT-3189 cells expressing GFP or GSE4. RNA was extracted and the expression of SOD1, Catalase (CAT), and SOD2 studied with TaqMan probes by RT-qPCR using C736 as a control. Expression of $\beta$-actin was used as a control and the relative expression of each gene to $\beta$-actin represented. Asterisks indicate significant differences in relation to control cell lines JY, AT-719, AT-L137IIB, and

2
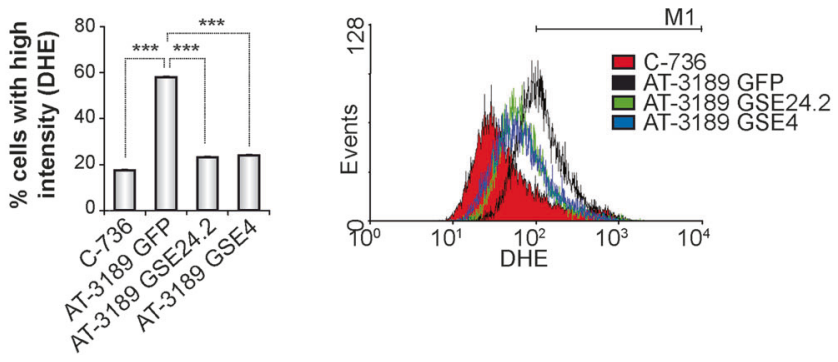

b
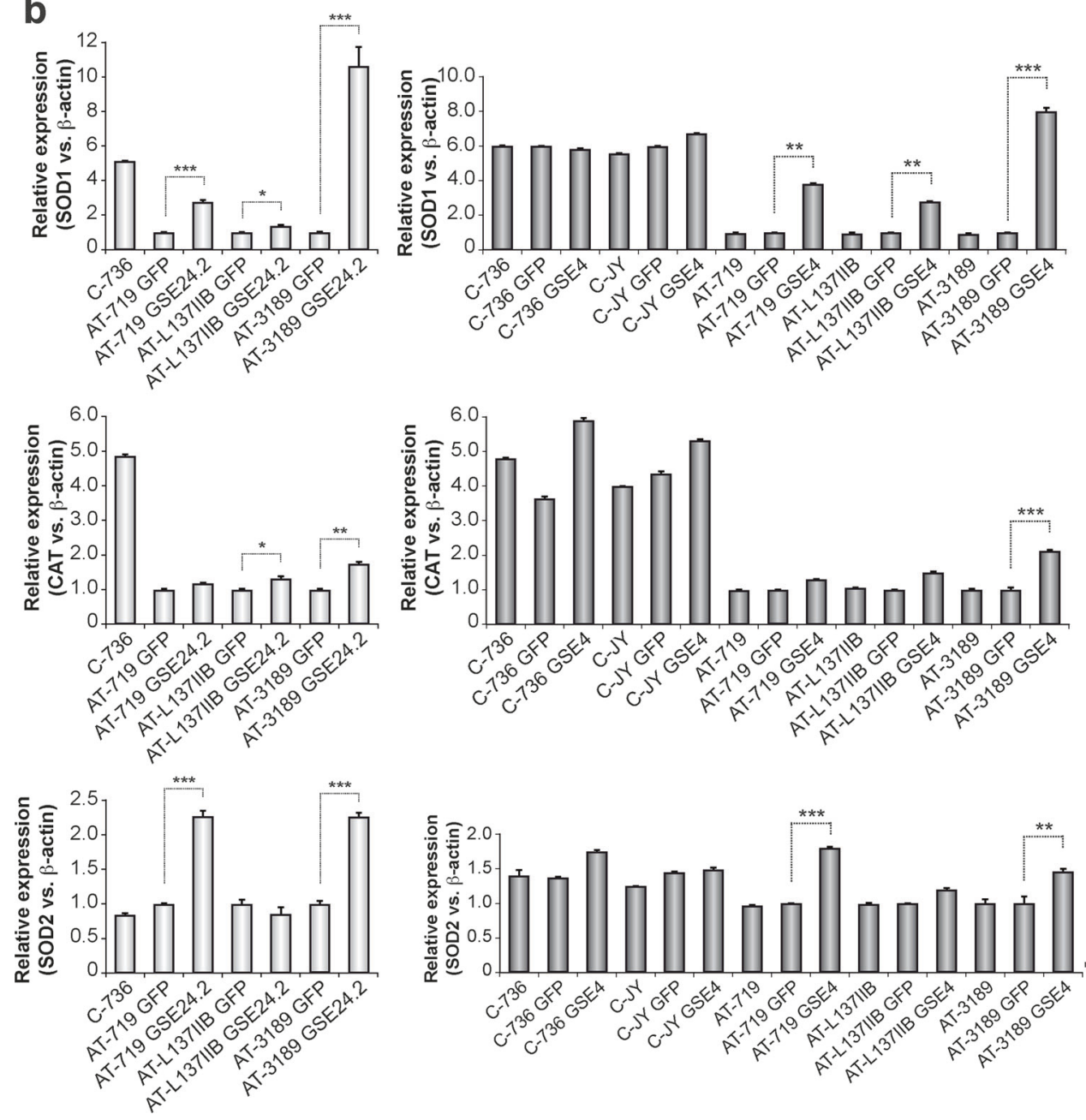

GSE24.2 or GSE4 estimated in relation with eGFP-expressing cells (Fig. 5c and Fig S5a). The results indicated that expression of GSE24.2 or GSE4 was able to prolong growth of AT lymphoblasts probably due to the lower levels of ROS and activated p38 in AT cells expressing these peptides.

AT cells are very sensitive to agents inducing DSBs such as ionizing radiation or bleomycin. We investigated if there was any protective effect to bleomycin with GSE24.2 or GSE4. Control and AT cells expressing either eGFP, GSE24.2, or GSE4 were treated with increasing doses of bleomycin and cell viability determined (Fig. 5d and Fig S5b).
Even though there was almost no effect in the viability of control cells expressing GSE24.2 or GSE4, the $\mathrm{IC}_{50}$ of AT cells expressing either peptides was always higher than that of AT-GFP cells, which was lower than in control cells.

\section{Recovery in TERT expression and telomerase activity in AT lymphoblast cells after GSE24.2/GSE4 expression}

AT patients have shortened telomeres and increased frequency of chromosome end-to-end fusions (CEFs) [26, 27]. 


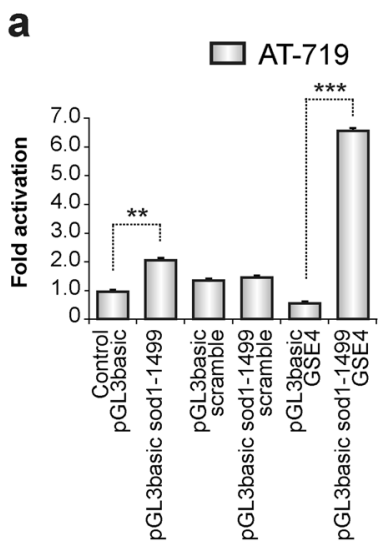

AT-3189

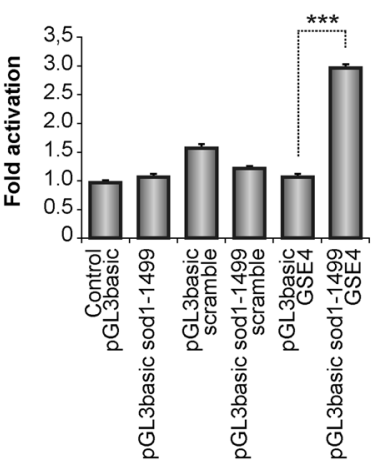

b

$\square$ c-736
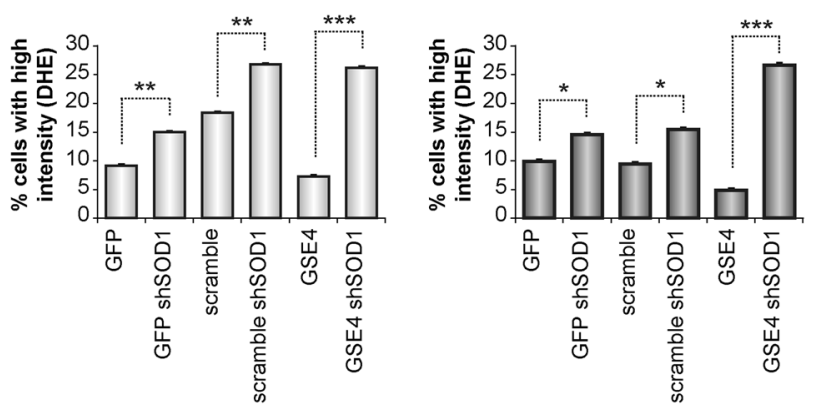
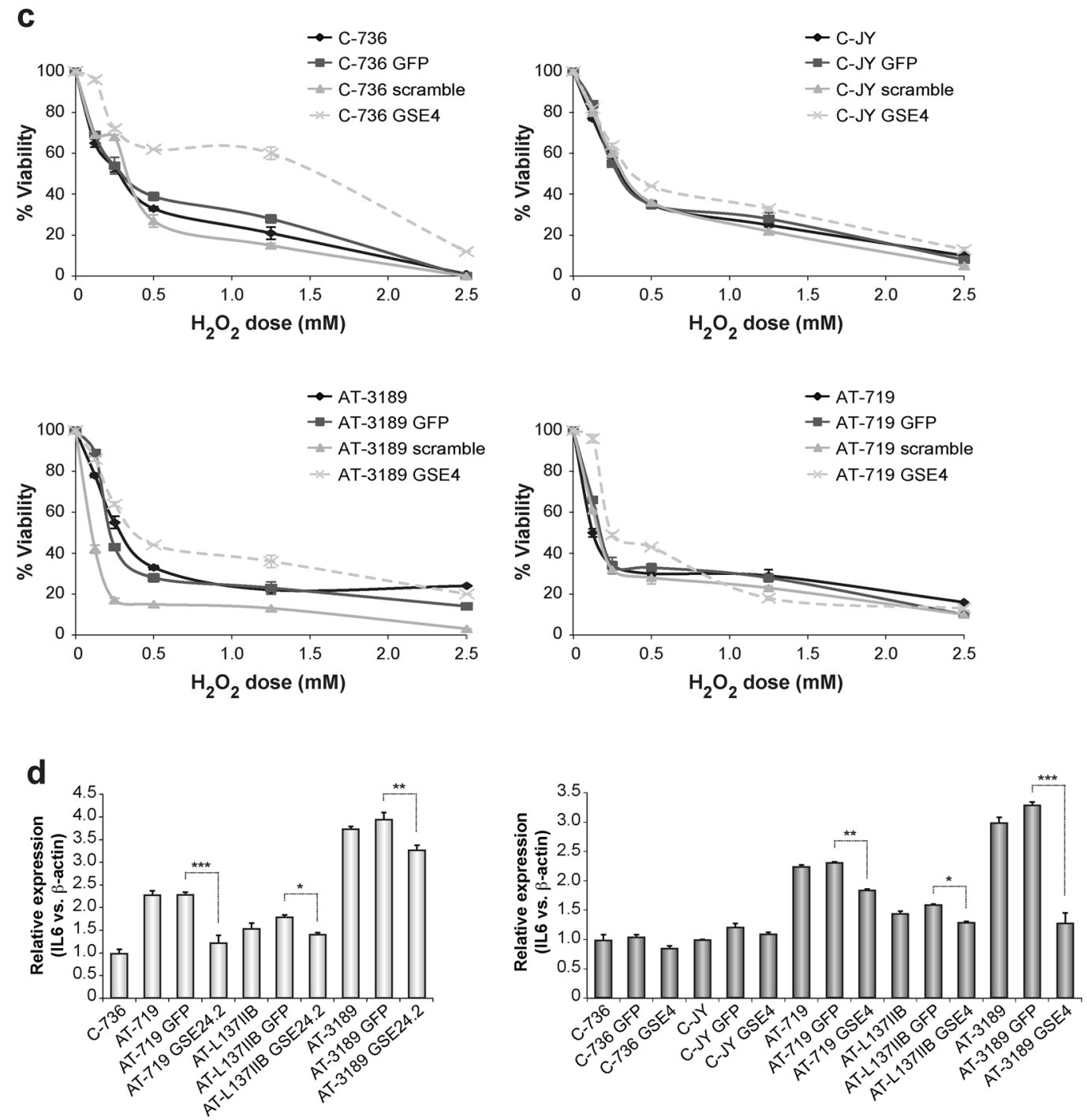

We have evaluated the expression of TERT, TERC, and DKC1 and found that expression of TERC (Fig. 6a) was higher in some AT cell lines than in control cells, expression of DKC1 did not show major differences (Fig S6a), but the expression of TERT was very low in most AT cell lines studied (Fig. 6a). Expression of GSE24.2 or GSE4 in AT cells resulted in non-homogeneous changes in TERC (Fig. 6b) or DKC1 (Fig S6a), but TERT expression was 
Fig. 4 Activation of superoxide dismutase 1 (SOD1) promoter and role of SOD1 in ataxia telangiectasia (AT) cells expressing GSE24.2 or GSE4. IL6 expression. a Activation of human SOD1 promoter by GSE4. A-719 and A-3189 cells were co-transfection with an expression vector for scramble or GSE4 and luciferase reporter constructs pGL3basic or pGL3basic-sod1-1499 (containing the complete human sodl promoter). After $24 \mathrm{~h}$ from transfection, the cells were maintained in low serum for $16 \mathrm{~h}$ and then lysed and analyzed for luciferase activity. The figure shows folds of increase in luciferase activity over the promoterless vector pGL3basic. Experiments were repeated three times with similar results. A representative experiment is presented. Asterisks indicate significant differences in relation to control cell lines. b Inhibition of SOD1 expression in AT cells. C-736 and AT3189 cells expressing scramble, GFP or GSE4 were transduced with pGKshSOD1 lentiviral vector and cells were used to determine the percentage of cells with high intensity with DHE as represented. The experiments were performed in triplicates and repeated three times with similar results. Asterisks indicate significant differences in relation to control cell lines. c Effect of $\mathrm{H}_{2} \mathrm{O}_{2}$ treatment on viability of AT cells. C-736, C-JY, AT-719, and AT-3189 cells expressing GFP, scramble or GSE4 were treated by triplicate, with the indicated concentrations of $\mathrm{H}_{2} \mathrm{O}_{2}$ for $72 \mathrm{~h}$ and the percentage of live cells was determined by MTT assay. The experiment was repeated three times with similar results. A representative experiment is presented. d Expression levels of IL6 in cell lines described in (3b). IL6 and $\beta$-actin Taqman probes were used to determine the relative expression of IL- 6 in comparison with $\beta$-actin. The experiments were repeated three times with similar results and average values and standard deviations of representative experiment showed. Asterisks indicate significant differences in relation to control cell lines

increased in all AT cells (Fig. 6b). Dyskerin protein levels showed no significant changes in control and AT cells expressing either GSE24.2 or GSE4 (Fig S6b). As dyskerin is involved in pseudouridylation and processing of ribosomal RNAs (rRNAs), we determined the expression levels of rRNAs (45S, 28S, $18 \mathrm{~S}$, and 5.8S) in control and AT cells expressing GFP, GSE24.2, or GSE4 (Fig S7). There was an increase in the expression of 28S rRNA in most AT cells expressing GSE24.2 or GSE4 but there was no correlation with decreased expression level of $45 \mathrm{~S}$ rRNA or increased levels of $18 \mathrm{~S}$ or $5.8 \mathrm{~S}$ rRNAs as could be expected if GSE peptides would affect rRNA processing.

In agreement with the results on TERT expression, telomerase activity in AT-3189 cells was $40 \%$ lower than in control C-736 cells (Fig. 6c). Expression of GSE4 in AT3189 cells increased telomerase activity by $60 \%$, correlating with increased TERT expression (Figs. 6b, c).

We next studied telomere length (TL) in two AT cell lines (AT-3189 and AT-719) by Southern blot. The results clearly showed that, the mean TL was around 5 and $4.5 \mathrm{kbp}$ in AT patient-derived cells and $10-12 \mathrm{kbp}$ in a control cell line derived from an older proband (Fig. 6d). GSE4 expression induced changes in TL after 2 months of in vitro culture (Fig. 6d). We used quantitative polymerase chain reaction (qPCR) to measure those changes, as it is more sensitive than Southern blot for small TL changes [27]. We observed an increase in the $\mathrm{T} / \mathrm{S}$ ratio (the ratio of telomere $(\mathrm{T})$ repeat to single-copy (S) gene (36B4) copy numbers) in AT-3189 GSE4 cells after 60 days of culture. Using a conversion from $\mathrm{T} / \mathrm{S}$ ratio to kbp obtained with a reference DNA from MCF-7 cells, we determined that, in AT-3189-GSE4 there was an increase of almost $0.5 \mathrm{kbp}$ of TL (Fig. 6d table). Similar results were obtained using another single-copy gene human beta globin (HBG) (data not shown). Therefore, the increase in TERT expression and in telomerase activity by GSE4 expression resulted in telomere elongation.

\section{Changes in telomere and mitochondrial DNA oxidation in AT cells induced by expression of GSE4}

OS accelerates telomere shortening [28, 29] during DNA replication and ultimately promote cellular senescence [30]. In vitro studies have shown that the $5^{\prime}$-GGG- 3 ' sequence in the $5^{\prime}$-TTAGGG- $3^{\prime}$ telomeric-DNA repeats is more prone to oxidation than other DNA sequences [31]. We next studied if GSE4 expression may modify telomere oxidation. To that end, we adapted the procedure described by O'Callaghan et al. [32] by measuring base excision repair (BER)-related lesions at telomeres and at mitochondrial DNA. This qPCR method is based on differences in PCR kinetics between DNA-template digested by formamidopyrimidine-DNAglycosylase (FPG) and undigested DNA. We have modified the original protocol by incorporating the human glycosidase from the BER pathway OGG1 that eliminates 8-oxoguanine in double-stranded DNA [33]. The results showed that the ratio of PCR amplification with vs. without OGG1 digestion (an indicator of 8-oxoguanine levels) in telomere regions were higher in cells after 60 days of culture. Basal levels of oxidation in the control cell line C-736 (T0) was higher than in AT-3189 (T0) probably due to the fact that TL in C-736 cells was twice longer than that of AT-3189 and therefore the abundance of G triplets. After 60 days, GSE4-expressing cells either control or AT had lower oxidation levels than at $\mathrm{T} 0$, but the effect was stronger in AT-T60 cells (Fig. 7a). Similar results were obtained when a probe to amplify the mitochondrial gene COX1 (Fig. 7b) was used. Expression of GSE4 resulted in a marked decrease in oxidation in COX1 gene, which was more evident in C-736-T60 and AT-3189-T0 and even more at T60. These results indicate that expression of GSE4 in AT cells decreases the level of 8-oxoguanine at telomeres and mitochondrial DNA suggesting an important decrease in oxidative DNA damage at different compartments.

\section{Discussion}

Several lines of evidence suggest that high levels of OS contribute to neurodegeneration in AT [34]. First, AT cells and tissues display abnormally high levels of OS and ROS 
a
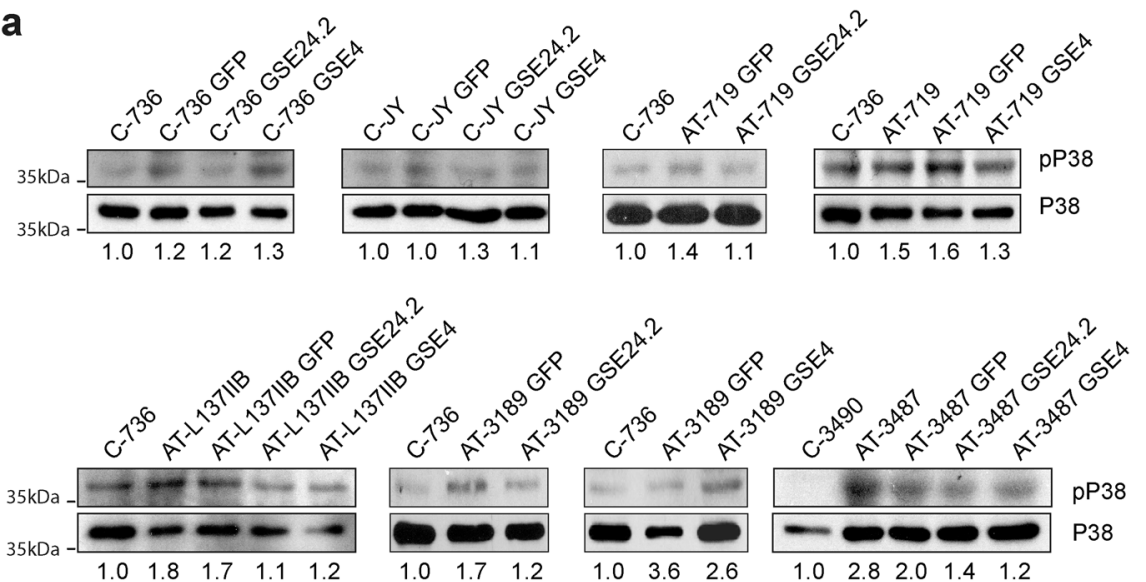

b

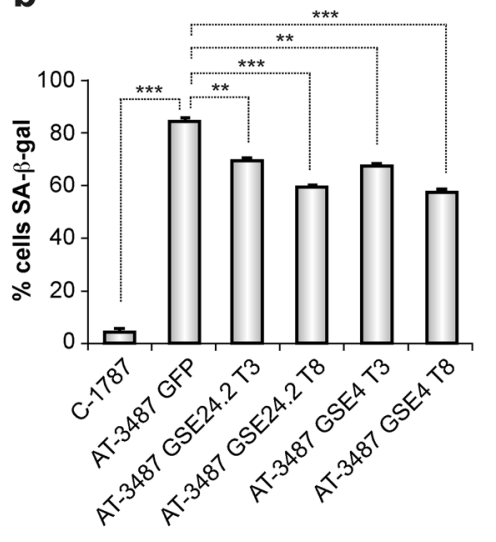

C
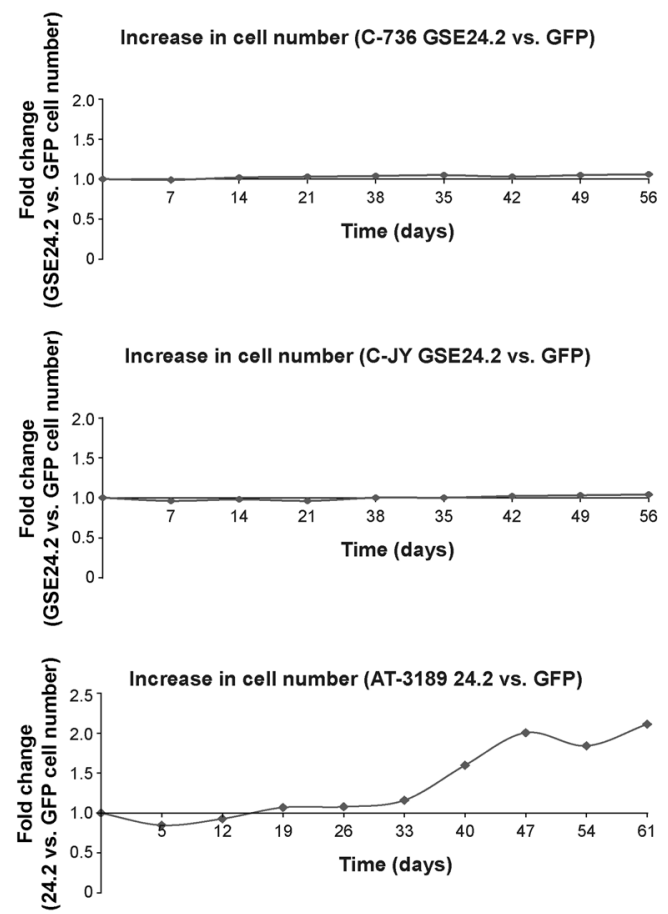
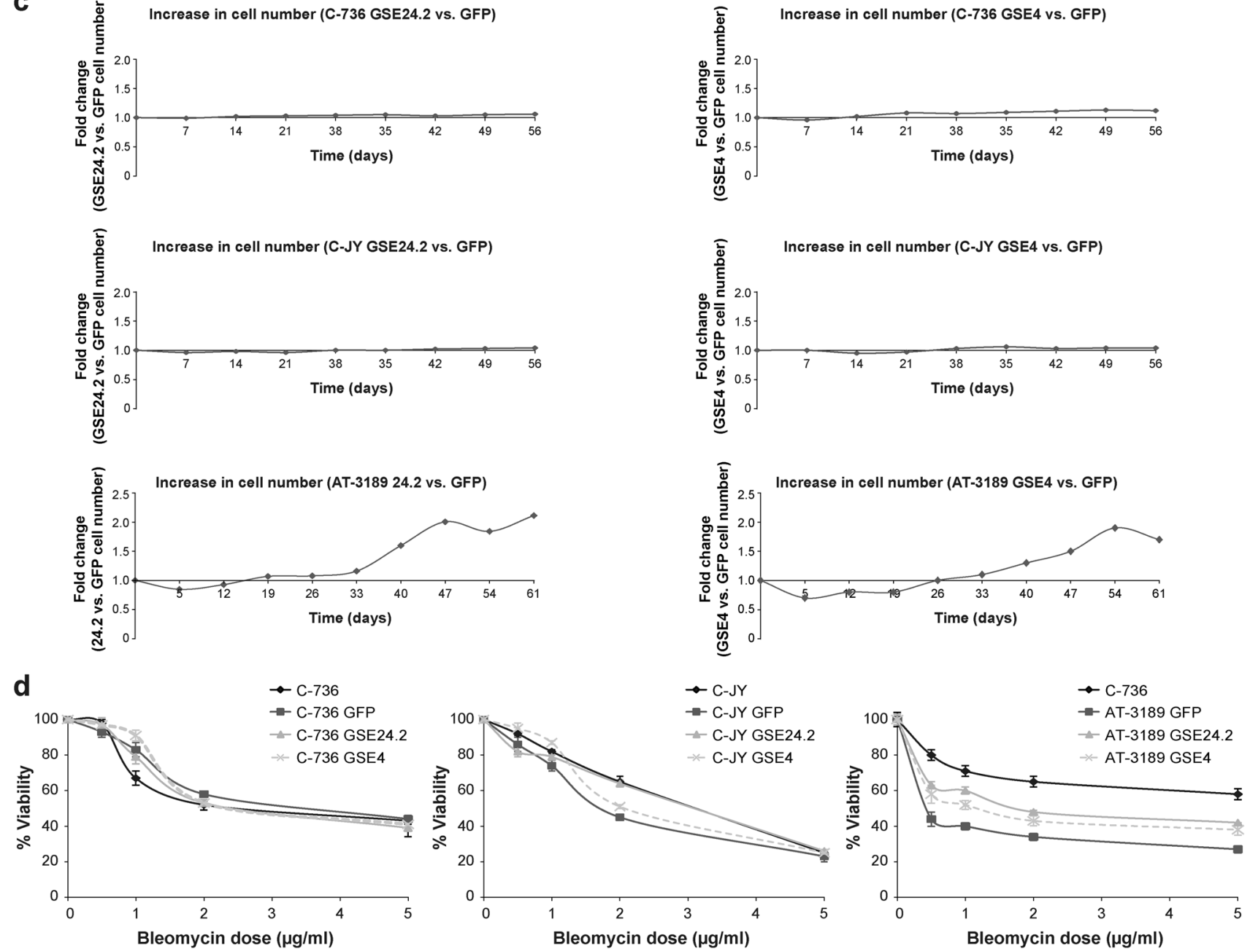

in the brain (particularly the cerebellum) [35, 36], oxidative DNA damage, and lipid oxidation products [37]. Second, AT cells and tissues are especially sensitive to ROSinducing agents (such as hydrogen peroxide and ionizing radiation) and have impaired DNA damage checkpoint responses, persistent DNA damage, and a lowered apoptosis threshold [38-40]. Finally, treatment of AT cells and tissues with antioxidants can improve cell and tissue survival. 
Fig. 5 Expression of phosphorylated p38, SA-ßgal activity, and viability in ataxia telangiectasia (AT) cells expressing GSE24.2 or GSE4. a Expression of phosphorylated p38. C-736, C-JY, AT-719, ATL137IIB, and AT-3189 and AT-3487 expressing GFP, GSE24.2, and GSE4 were used to obtain protein extracts and used for western blot analysis of expression of phospho-p38 by using an specific antibody. As a loading control the membranes were hybridized also with a p38 antibody. The ratio between expression detected by both antibodies is indicated below each western lane using C-736 cells as control. b Detection of expression of SA- $\beta$ gal. C-1787 control and AT patient AT-3487 cells were transduced with either LV-CMV-eGFP, LVCMV-GSE24.2-eGFP, or LV-CMV-GSE4-eGFP lentiviral vectors and cells were processed for detection of SA- $\beta$ gal expression 3 and 8 days after transduction (T3 and T8). The percentage of cells positive for $\beta$ gal is represented for each experimental condition using C-1787 cells as control. The experiments were repeated three times with similar results and average values and standard deviations of representative experiment showed. Asterisks indicate significant differences in relation to control cell lines. $\mathbf{c}$ Growth of AT cells expressing GSE24.2 or GSE4. C-736, C-JY and AT-3189 lymphoblasts were transduced with either LV-CMV-eGFP or LV-CMV-GSE24.2-eGFP (left panel) or LV-CMV-GSE4-eGFP (right panel) lentiviral vectors. Cells were allowed to grow and every week the number of cells was monitored and expressed as the ratio between cells infected with GSE24.2 or GSE4 to cells expressing GFP. Growth was monitored until 60 days after viral transduction. The experiment was repeated twice with similar results. d Cell viability to bleomycin. C-736, C-JY, and AT3189 lymphoblasts expressing GFP, GSE24.2, or GSE4 were exposed to increasing concentrations of bleomycin during $72 \mathrm{~h}$. After, the percentage of live cells was determined by MTT assay. C-736 cells were used as controls in every assay. The experiments were repeated three times with similar results and average values and standard deviations of representative experiment showed

Here we describe that expression of GSE24.2 or GSE4 peptides in AT cells mitigate many of the pathologic consequences of high ROS levels including telomere shortening. Indicators of DNA damage such as the histone $\gamma$ $\mathrm{H} 2 \mathrm{AX}$ and 53BP1 foci decreased in AT cells expressing GSE24.2 or GSE4. Levels of 8-oxoguanine residues also decreased, indicating reduced oxidative damage. Our previous results indicate that expression of both peptides decreased ROS and 8-oxoguanine levels in X-DC cells with high oxidative damage generated by telomere shortening $[18,19]$. Interestingly, expression of both peptides was unable to rescue the DDR and repair defect caused by ATM inhibition in $T d p 2^{-/-}$MEFs or primary human cells. Therefore, these peptides cannot rescue the effects of ATM inactivation on DSB signaling and repair, but importantly inhibit the accumulation of DNA oxidative damage.

ROS are endogenous agents causing DNA damage, and perform critical signaling functions in apoptosis, stress responses, and proliferation [41]. Cellular mechanisms protecting from ROS, include detoxifying enzymes such as superoxide dismutases (SODs), and small-molecule scavengers such as glutathione [42]. We have found lower SOD1 and catalase mRNA levels in AT than in control cells. Interestingly, expression levels increased in AT cells expressing GSE24.2 or GSE4, even in cells not showing deficient SOD2 expression. GSE4 was able to activate the SOD1 promoter revealing a possible mechanism for regulation of ROS levels by GSE peptides. Knock-down of SOD1 expression in AT-GSE4-expressing cells resulted in increased ROS levels, strongly suggesting that increased expression of SOD1 was at least partially responsible of the decrease in ROS levels. This cellular defense induced by GSE peptides results in protection to ROS scavengers such as $\mathrm{H}_{2} \mathrm{O}_{2}$. In agreement with our results, treatment of AT cells with antioxidant therapy corrects clinically important aspects of the disease [43].

We found increased levels of IL-6 in human AT cell lines in agreement with previous results [44]. Expression of GSE24.2 or GSE4 in AT cells decreased IL-6 expression. IL-6 mediates inflammation and contributes to the maintenance of the senescent phenotype, which might induce malignancy in neighboring cells specially in AT patients [44]. Increased p38-MAPK activation is also related with increased proinflammatory cytokine induction under continuous DNA damage conditions [44]. Expression of either GSE24.2 or GSE4 decreases the ratio of p38-activated/ unphoshorylated-p38 in AT cells. AT fibroblast cells expressing of GSE24.2 or GSE4 also showed lower expression of SA- $\beta$-gal, strongly indicating that the expression of both peptides can trigger inhibition of senescence-associated secretory phenotype (SASP)-related pathways activated in AT cells.

Immunodeficiency and bone marrow failure are severe effects of ATM loss in AT patients. We found that AT lymphoblasts expressing both peptides, were able to continuously divide during 2 months in contrast to unmodified AT cells suggesting beneficial effects counteracting the loss of B or T cells found in AT patients.

AT patients exhibit radiosensitivity and higher risk of cancers [45] between $10 \%$ and $38 \%$ of them developing at least one malignancy during lifetime [45]. AT patients also have high risk of developing secondary malignancies and serious chemotherapy-associated side effects such as severe mucosal inflammation or life-threatening infections. Therefore, radiotherapy is strongly discouraged in AT patients. Expression of GSE24.2 or GSE4 decreased sensitivity of AT cells to bleomycin, which may indicate a lower toxicity of radiation. Since increased ROS are also induced in response to radiomimetic drugs, we suggest that the antioxidant capacity of both peptides may contribute to this protective effect.

AT is classified as a secondary telomere disease even if mutations are not detected in telomere regulatory genes [46]. We have found that decreased TL in AT cells is probably partially due to decreased expression of the catalytic telomere subunit TERT. In addition, 8-oxoguanine is present in high levels, which might contribute to telomere attrition. Expression of GSE24.2 and GSE4 induced a small 
a
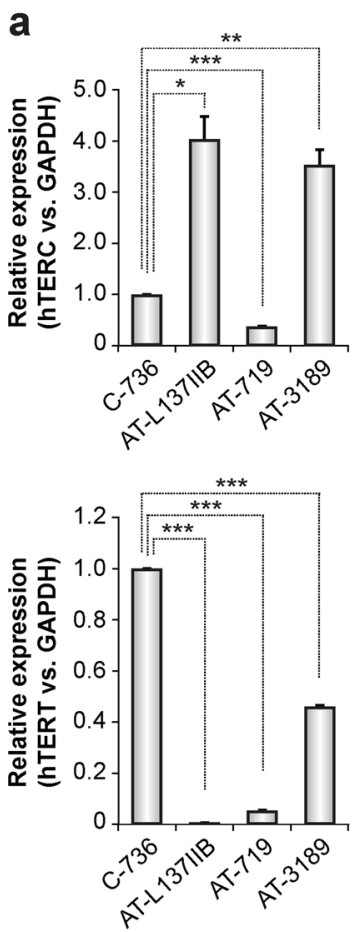

C

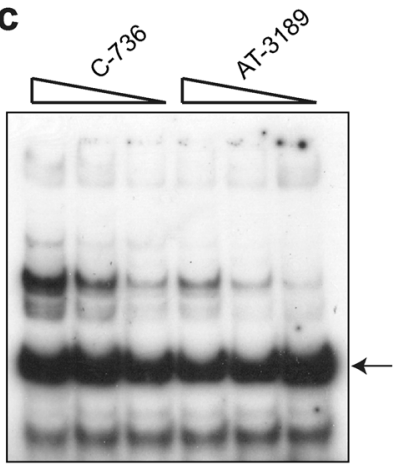

d

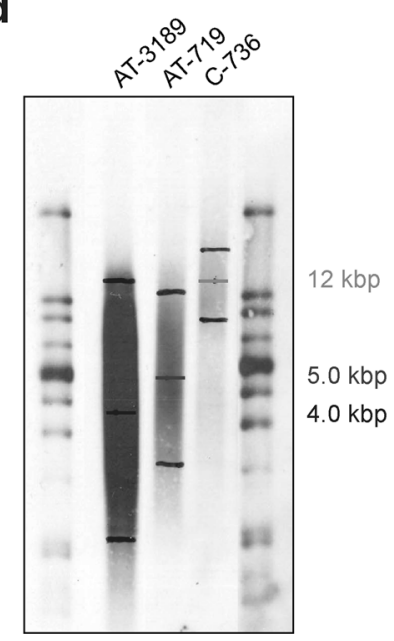

b
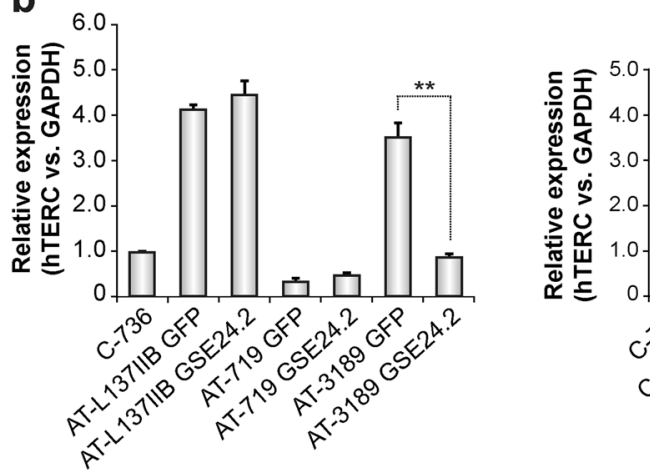

o四, П П П

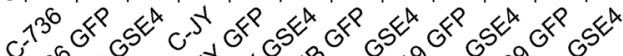
$0^{13^{3}} 0^{13^{20}}$
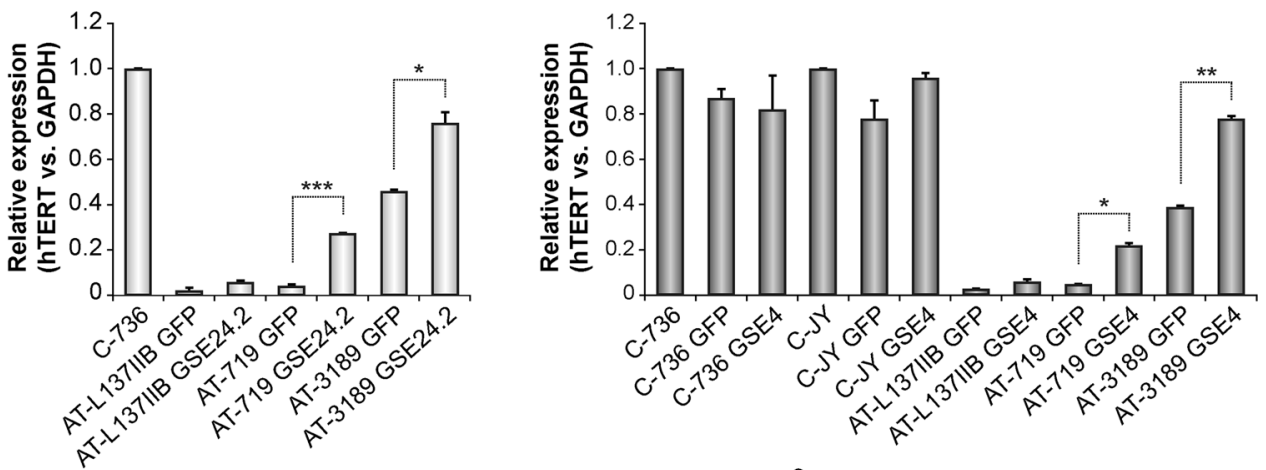
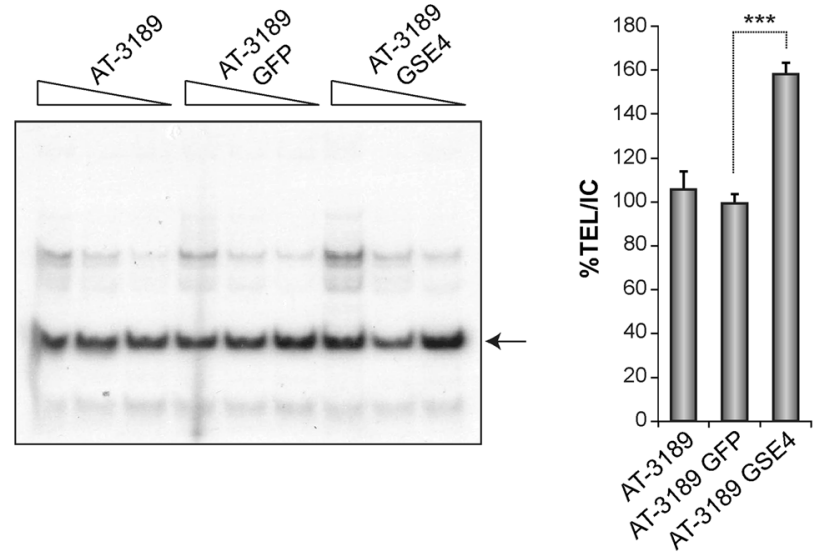

\begin{tabular}{c|c|c}
\hline DNA & $\begin{array}{c}\text { Mean Tel length } \pm \text { SD } \\
\text { (T/S ratio) }\end{array}$ & $\begin{array}{c}\text { Mean Tel length } \pm \text { SD } \\
\mathrm{kbp}(1 \mathrm{~T} / \mathrm{S}=4.8 \mathrm{kbp})\end{array}$ \\
\hline C-736 & $1.669 \pm 0.089$ & $8.009 \pm 0.426$ \\
AT-3189 GFP & $0.950 \pm 0.001$ & $4.559 \pm 0.002$ \\
\hline AT-3189 GSE4 & $1.034 \pm 0.007$ & $4.965 \pm 0.033$ \\
\hline
\end{tabular}


Fig. 6 Expression of telomere genes, telomerase activity, and telomere length in ataxia telangiectasia (AT) cells expressing GSE24.2 or GSE4. a Expression of TERT and TERC. RNA was extracted from C-736 control and AT-7191, L137IIB, and AT-3189 AT cells and the expression levels of TERT and TERC determined by RT-qPCR. The expression level of the control cell line was considered as 1 . b Expression TERT and TERC in AT-719, AT-L137IIB, and AT-3189 cells expressing GFP or GSE24.2 and C-736, C-JY, AT-719, AT-L137IIB, and AT-3189 cells expressing GFP or GSE4. RNA was extracted and the expression of TERT and TERC determined by RT-qPCR. The expression level of the control cell line C-736 was considered as 1. In (a and $\mathbf{b})$, the experiments were repeated three times with similar results and average values and standard deviations of representative experiment showed. Asterisks indicate significant differences in relation to control cell lines. c Telomerase activity in AT cells. Control (C-736) and AT-3189 AT patient-derived cells were assayed for telomerase activity using the TRAP assay. Different amounts of extract were used for each TRAP assay as indicated. The activity was quantified by evaluating the intensity of the bands (TEL) in relation with the internal control (IC) (indicated by an arrow at the right of the panel) (TEL/IC) (two left panels). AT-3189 AT cells expressing GFP or GSE4 were assayed for telomerase activity using the TRAP assay. The activity was quantified by evaluating the intensity of the bands in relation with the internal control as above. The experiments were repeated three times with similar results and average values and standard deviations of representative experiment showed. $\mathbf{d}$ Telomere length in AT cells. Genomic DNA was obtained from C-736 and AT-3189, AT-719 AT patient-derived cells and telomere length analyzed by Southern blot using a telomere probe. The median telomere length for each cell line is indicated at the right of the gel (left panel). C-736, AT-3189, and AT-3189 cells transduced with LV-CMV-eGFP or LV-CMV-GSE4-eGFP lentiviral vectors and 60 days after transduction and telomere length studied by telomere specific qPCR (right panel). The table indicated the mean ratio obtained between telomere and single-copy gene expression and the corresponding standard deviations (Mean TL length (T/S ratio)), the mean telomere length in kbp (using as a reference the DNA of MCF-7 cells) using the conversion formula $1 \mathrm{~T} / \mathrm{S}$ equivalent to $4.8 \mathrm{kbp}$ and the corresponding standard deviations. Experiments were performed by triplicates and repeated twice with similar results

but reproducible increase in TERT expression, resulting in a $50 \%$ increase in telomerase activity and a rate of telomere elongation of $0.5 \mathrm{kbp}$ in 2 months. This protective effect is also associated with lower oxidation in telomere and mitochondrial DNA. This last finding may explain how GSE4 expression could contribute to less ROS production at mitochondria thus enforcing the protective effect of GSE peptides.

In summary, our results indicate that GSE4 could be used in the treatment of $\mathrm{AT}$ patients, inducing protection to OS, decreasing oxidative damage at DNA, inflammationassociated parameters, senescence and increasing the viability to ROS scavengers, and radiomimetic drugs. Decreased oxidative DNA damage may result in attenuation of malignancies associated with AT and also to decreased bone marrow failure, a pathology that increased morbidity in AT patients. A second therapeutic advantage would be the effects of telomerase activation, reduced telomere oxidative damage, and telomere elongation that would result in
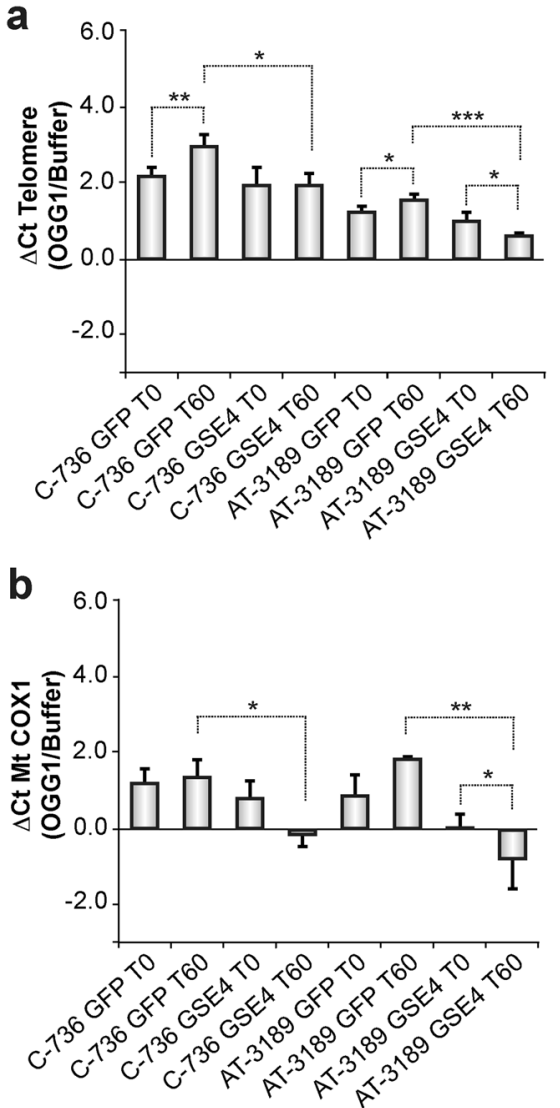

Fig. 7 Telomere and mitochondrial DNA oxidation in ataxia telangiectasia (AT) cells and the effect of GSE4 expression. a Telomere oxidative DNA damage (OGG1-derived lesions) in control C-736 cells and AT-3189 cells transduced with LV-CMV-eGFP (GFP) or LVCMV-GSE4-eGFP at $48 \mathrm{~h}$ (T0) or 60 days (T60) after transduction. b Oxidative DNA damage (OGG1-derived lesions) at COX1 mitochondrial region in cells described in (a). The differences in PCR kinetics $(\mathrm{Ct})$ between OGG1-digested vs. undigested DNA (Buffer) is represented for each sample in triplicate. Errors bar for standard deviation are represented

maintenance of cell proliferation and reduction of genomic instability.

\section{Materials and methods}

\section{Cell lines and cell culture}

Cell lines, both control and those derived from AT patients, were obtained from Coriell Cell Repository (Camden, NJ). We used control human fibroblasts GMO1787 (C-1787) and C-3490 and AT fibroblasts GMO3487 (AT-3487, 8 years). This cell line carries an $\mathrm{A}>\mathrm{T}$ substitution at nucleotide 8266 $(8266 \mathrm{~A}>\mathrm{T})$ in exon 58 resulting in a truncation at codon 2756 [Lys2756Ter (K2756X)], whereas the paternal allele carries a 4-bp insertion at nucleotide 1141 in exon 11 resulting in a frameshift at codon 381 leading to a truncation 
(S381fsX). Lymphoblast cells were also obtained from Coriell: GMO736 (C-736, 30 years) from a healthy donor and CJY cells (ATCC, Manassas, VA USA), and two from AT patients GMO3189 (A>T substitution at nucleotide 8266 (8266A > T, 7 years) and GMO719 (AT-719, 13 years) [47]. AT-L137IIB lymphoblast cells were obtained in our lab from an AT patient (ATM:c.103C > T; p.R35X; rs55861249, 11 years). Primary MEFs were isolated from $T d p 2^{-/-}$embryos [48] at day 13 post coitum (p.c.) and cultured at $37^{\circ} \mathrm{C}, 5 \%$ $\mathrm{CO}_{2}, 3 \% \mathrm{O}_{2}$. All primary fibroblasts were maintained in Dulbecco's modified Eagle's medium (Gibco) supplemented with $10 \%$ fetal bovine serum (FBS), gentamicin and L-glutamine and lymphoblasts cells in RPMI (Roswell Park Memorial Institute medium) supplemented with 20\% FBS, gentamicin and L-glutamine.

\section{Lentiviral vectors for GSE24.2, GSE4, and shSOD1 expression}

All lentiviral vectors (LVs) used in these experiments were third-generation sin-LVs. The fragments scramble peptide, GSE24.2, and GSE4 were cloned into the pRRLsin18.ppt. CMV.IRES.eGFP transfer vector using the PstI and BamHI restriction sites. GSE4 was cloned as double-stranded oligonucleotides as described [19]. The DNA coding for a scrambled peptide containing the same amino acids as GSE4 arranged randomly was cloned between the Pst I and BamHI restriction sites of the same vector using the annealed oligonucleotides 5'-GATGCTTTCTAAGGGTAATAACATTCC CGACTTCCCCTAAG-3' and 5'-GATCCTTAGGGGAAG TCGGGAATGTTATTACCCTTAGAAAGCATCTGCA-3'. The original pRRLsin18.ppt.CMVeGFPWpre transfer vector, pMDLg-pRRE and pRSV-REV packaging vectors, and pMD2-VSVG envelope vector were kindly provided by Dr. Luigi Naldini (San Raffaele Telethon Institute for Gene Therapy, University Medical School, Milan, Italy). The LVs supernatants (LV-CMV-eGFP, LV-CMV-scramble-eGFP, LV-CMV-GSE24.2-eGFP, LV-CMV-GSE4-eGFP) and pGKshSOD1 (Sigma-Aldrich-Merck, St. Louis, MO, USA) were produced using a viral packaging system that includes the packaging and envelope vectors in 293T cells and used for transduction of the indicated cell lines. Efficiency of transduction was monitored by flow cytometry detecting expression of eGFP. Expression of GSE24.2, GSE4, and SOD1 was quantified by RT-qPCR using oligonucleotides previously reported [19].

\section{Nanoparticle synthesis and loading of GSE24.2 and GSE4 peptides}

Chemically synthesized GSE4 and GSE24.2 peptides labeled with fluorescein-5-isothiocyanate (FITC) were obtained from China Peptides (Hangzhou, China) and purified by high-performance liquid chromatography (HPLC). poly(lactic-co-glycolic acid/Poly(ethylenimine) (PLGA/PEI) nanoparticle preparation and peptide loading was performed as previously described [20]. Internalization efficiency was estimated by determination of intracellular fluorescence using a fluorescence enzyme-linked immunoSorbent assay (ELISA) reader.

\section{Determination of ROS content with dihydroethidium}

Cells were washed two times with pre-warmed phosphatebuffered saline (PBS) medium and $2 \mu \mathrm{L} / \mathrm{mL}$ of diluted dihydroethidium (D7008-Sigma-Aldrich-Merck, St. Louis, MO, USA) was added to the plate. Cells were incubated at $37^{\circ} \mathrm{C}$ for $20 \mathrm{~min}$ and then washed with PBS. Medium was replaced and cells cultured for an additional $1 \mathrm{~h}$ at $37^{\circ} \mathrm{C}$. The fluorescence was measured using spectraMAX GEMINIS (Molecular Device, Sunnyvale, USA), with 530 $\mathrm{nm}$ of excitation wavelength and $610 \mathrm{~nm}$ of emission wavelength. Mean fluorescence intensity (MFI) for each cell line was normalized by the cell number.

\section{Real-time quantitative PCR}

\section{RNA isolation and CDNA synthesis}

Total cellular RNA was extracted using Trizol (InvitrogenThermo, Carlsbad, USA) according to the manufacturer's instructions. Reverse transcription (RT) reactions were made using $1 \mu \mathrm{g}$ of the purified RNA using random hexamers and the High-Capacity cDNA Archive kit (Applied Biosystems-Thermo Fisher, P/N: 4322171; Foster City, CA) according to the manufacturer's instructions.

\section{Measurement of mRNA levels}

The mRNA levels were determined by quantitative realtime PCR analysis using an ABI Prism Step One Plus PCR System (Applied Biosystems-Thermo Fisher, Foster City, CA). Gene-specific primer pairs and probe for IL-6 (Hs00985639_m1), $\beta$-actin: Hs99999903_m1, catalase Hs00156308_m1, SOD1: Hs00533490_m1, SOD2: Hs00167309_m1 were used together with TaqMan ${ }^{\circledR}$ Universal PCR Master Mix (Applied Biosystems-Thermo Fisher, P/N 4304437, Foster City, CA) and $2 \mu$ of reverse transcribed RNA in $20 \mu$ reaction volume. PCR conditions were $10 \mathrm{~min}$ at $95^{\circ} \mathrm{C}$ for enzyme activation, followed by 40 two-step cycles $\left(15 \mathrm{~s}\right.$ at $95^{\circ} \mathrm{C} ; 1 \mathrm{~min}$ at $\left.60^{\circ} \mathrm{C}\right)$. The levels of beta-actin $(\beta$-act) expression were measured in all samples to normalize gene expression for sample-to-sample differences in RNA input, RNA quality, and reverse transcription efficiency. Expression of TERT, TERC, DKC1, GAPDH 
and $45 \mathrm{~S}, 28 \mathrm{~S}, 18 \mathrm{~S}$ and $2.5 \mathrm{~S}$ rRNAS were performed with the following oligonucleotides:

TERT F 5'-CGGAAGAGTGTCTGGAGCAA-3'; TERT R 5'-GGATGAAGCGGAGTCTGG-3';

TERC F 5'-TCTAACCCTAACTGAGAAGGGCGTA G-3'; TERC R 5'-GTTTGCTCTAGAATGAACGGTGGA AG-3';

DKC1 F 5'-GCTCCTCAGTTGATCAAGAAGG-3';

DKC1 R 5'-CTCAGAAACCAATTCTACCTC-3'; 45S F 5'-GGACGTGCCGCGCCAGGAAG-3'; 45S R 5'-CGACGCTCAGACAGGCGTAG-3';

28S F 5'-GCCAAGCGTTCATAGCGACG-3'; 28S R 5'-CTGAGCAGGATTACCATGGC-3';

18S F 5'-GGACACGGACAGGATTGACAG-3'; 18S R

5'-CAATCTCGGGTGGCTGAACG-3';

5.8S F 5'-GACTCTTAGCGGTGGATCAC-3'; 5.8S R

5'-CGACGCTCAGACAGGCGTAG-3'.

GAPDH F 5'-GAGAGACCCTCACTGCTG-3'; GAPDH R 5'-GATGGTACATGACAAGGTGC-3'. Specific oligonucleotides were used together with Power Sybrgreen PCR mastermix (Applied Biosystems-Thermo Fisher, P/N 4304437, Foster City, CA) and $2 \mu$ of reverse transcribed RNA in $20 \mu \mathrm{l}$ reaction volume. PCR conditions were $10 \mathrm{~min}$ at $95^{\circ} \mathrm{C}$ for enzyme activation, followed by 40 two-step cycles $\left(15 \mathrm{~s}\right.$ at $95^{\circ} \mathrm{C} ; 1 \mathrm{~min}$ at $\left.60^{\circ} \mathrm{C}\right)$. The levels of GAPDH expression were determined in all samples to normalize gene expression for sample-to-sample differences in RNA input, RNA quality and reverse transcription efficiency. Each sample was analyzed in triplicate, and the expression was calculated according to the $2^{-\Delta \Delta \mathrm{Ct}}$ method.

Repair kinetics In all, $3 \times 10^{5} \mathrm{Tdp}^{-/-}$primary MEFs were infected with LV-CMV-eGFP, LV-CMV-GSE24.2-eGFP, or LV-CMV-GSE4-eGFP (MOI 10) in T25 flasks, incubated for 3 days, and then grown on coverslips for 7 days until confluence. Cells were then treated $30 \mathrm{~min}$ with etoposide $(10 \mu \mathrm{M})($ Sigma) in the presence or absence of 10 $\mu \mathrm{M}$ ATMi (KU55933) (Tocris Bioscience). ATMi was maintained at 3 and $6 \mathrm{~h}$ after washing the etoposide. Repair analysis was carried out by monitoring the time course of $\gamma$ $\mathrm{H} 2 \mathrm{AX}$ foci disappearance following drug (etoposide) removal. C-1787 and C-3490 cells were treated 30 min with bleomycin $(1 \mu \mathrm{M})$ (Sigma-Aldrich-Merck) in the presence or absence of $10 \mu \mathrm{M}$ ATMi (KU55933) (Tocris Bioscience). ATMi was maintained at 6 and $24 \mathrm{~h}$ after washing the bleomycin. Repair analysis was carried out by monitoring the time course of $\gamma-\mathrm{H} 2 \mathrm{AX}$ foci persistence following drug (bleomycin) removal.

\section{Immunofluorescence}

Protein localization was carried out by fluorescence microscopy. For this purpose, cells were grown on coverslips, transfected and fixed in $3.7 \%$ formaldehyde solution (47608; Fluka, Sigma-Aldrich-Merck, St. Louis, $\mathrm{MO})$ at room temperature for $15 \mathrm{~min}$. After washing with $1 \times$ PBS, cells were permeabilized with $0.2 \%$ Triton X-100 in PBS and blocked with $10 \%$ horse serum before overnight incubation with $\gamma$-H2A.X (05-636; Merck Millipore), 53BP1 (4937; Cell Signaling), and 8-oxoguanine antibodies (MAB2560; Merck Millipore). Finally, cells were washed and incubated with secondary antibodies coupled to fluorescent dyes (Alexa fluor 488 or/and Alexa fluor 647). Images were acquired with a Confocal Spectral Leica TCS SP5 using a HCX PL APO Lambda blue 6361.40 OIL UV, zoom 2.3 lens. Images were acquired using LAS-AF 1.8.1 Leica software and processed using LAS-AF 1.8.1. Leica software and Adobe Photoshop CS. Each experiment was performed in triplicates and at least 200 cells were quantified for each experimental condition.

\section{Western blot and antibodies}

Whole-cell extracts were prepared essentially as described previously [49]. Western blotting was performed using standard methods [49]. Protein concentration was measured by using the Bio-Rad protein assay.

The source of antibodies was as follows: phosphoHistone H2A.X Ser139 (2577) Cell Signaling, monoclonal anti- $\beta$-actin (A2228) from Sigma-Aldrich-Merck, SOD1 (HPA001401) Sigma-Aldrich-Merck, p38 (C-20) and dyskerin $(\mathrm{H}-300)$ from Santa Cruz Biotechnology and p38 (Th180/tyr182 (9211) from Cell Signaling.

\section{Senescence analysis}

Control and AT fibroblasts $\left(1 \times 10^{4}\right.$ cells $)$ were plated onto six-well plates and fixed after 4 days to assay the SA- $\beta$-gal activity (Senescence Detection Kit, BioVision, Milpitas, California). The percentage of senescent cells was calculated in six images per sample taken by bright field microscopy at $\times 100$ magnification (Nikon Eclipse TS100 Microscope, Melville, NY, USA).

\section{Telomeric repeat amplification protocol (TRAP) assay}

Telomerase activity was determined under recommended standard conditions of the TRAPEZE ${ }^{\circledR}$ Telomerase Detection S7700 Kit (Merck Millipore) for TRAP using radioisotopic detection. Telomerase activity was determined in each sample using $0.5,0.25$, and $0.125 \mu \mathrm{g}$ of protein extract and normalized with the internal control included in the assay [13]. 


\section{TL analysis}

TL was determined from DNA of cells, either control or AT, by Southern blot analysis of telomere restriction fragment (TeloTAGGG Telomere Length Assay, SigmaAldrich-Merck), which is considered the gold standard to determine TL as previously described [50]. The relative TL was assessed by qPCR as previously described [28]. The qPCR determines the ratio of telomere (T) repeat copy number to single-copy (S) gene (36B4) copy number (T/S ratio) in experimental samples, as compared with a reference DNA sample (MCF-7 cells).

\section{Oxidative DNA damage within telomeres and mitochondrial DNA}

We adapted the procedure described by O'Callaghan et al. [32] to measure oxidative DNA damage at telomeres, 36B4 genomic region and at mitochondrial DNA. This is a qPCR method based on differences in PCR kinetics between DNA template digested by FPG and undigested DNA. We have modified the original protocol to incorporate another purified human DNA glycosylase from the BER OGG1 (kindly provided by Professor Thomas Helleday's Lab, Karolinska Institutet, Sweden) to quantify the accumulation of base lesions specific for OGG1, 8-oxoguanine. This enzyme recognizes and cuts 8-oxoguanine producing apurinic sites (AP) that are converted in single-strand breaks (SSBs) by its AP lyase activity. These SSBs inhibit the PCR, thus, the $\triangle \mathrm{CT}$ after digesting DNA by 8-oxoguanine (Ct digested-Ct undigested) is proportional to the oxidative damage in the amplified region. Conditions used for incubation were $2.4 \mu \mathrm{M}$ OGG1 during $4 \mathrm{~h}$. The quantitative real-time amplification of genomic DNA was performed as described by O'Callaghan et al. [32]. Each $20 \mu \mathrm{L}$ qPCR were composed as follows: $40 \mathrm{ng}$ of digested or undigested genomic DNA, $1 \times \mathrm{GoTaq}^{\circledR}$ qPCR Master Mix (Promega), specific primers for each genomic region at a final concentration of $100 \mathrm{nM}$ (Mitochondrial COX1 F: 5'-CACAGCCCATGCATTTGTAA-3'; COX1 R: 5'-GATGCGAGCAGGAGTAGGAG-3' and Telo1/2 and 36B4 F/R) [32] Amplification cycling conditions were $10 \mathrm{~min}$ at $95^{\circ} \mathrm{C}$, followed by 40 cycles of $95^{\circ} \mathrm{C}$ for $15 \mathrm{~s}$ and $60^{\circ} \mathrm{C}$ for $1 \mathrm{~min} . \Delta \mathrm{CT}$ method was run in an ABI quant studio 7 and all samples were loaded and analyzed in triplicate.

\section{Luciferase assays}

Cells were seeded in 24-well plates (75,000 cells per well), cultured for $16 \mathrm{~h}$, and transfected with a DNA mixture consisting of $100 \mathrm{ng}$ of the appropriate luciferase construct (pGL3basic or pGL3basic-sod1-1499 containing the complete SOD1 promoter) [51] and $400 \mathrm{ng}$ of the GSE or scramble plasmid vectors, using Lipofectamine reagent (Invitrogen-Thermo Fisher, Carlsbad, CA) according to the manufacturer's recommendations. After $24 \mathrm{~h}$ from transfection, the cells were serum starved for $16 \mathrm{~h}$, lysed, and assayed for luciferase activity with the Luciferase Assay System (Promega) according to the manufacturer's instructions; relative light units were measured in a BG1 Optocomp I, GEM Biomedical luminometer (Sparks, NV).

\section{Viability and cell growth assays}

Briefly, cells were treated in 96-multiwell dishes with increasing concentrations of bleomycin or $\mathrm{H}_{2} \mathrm{O}_{2}$. Cell viability was estimated by MTS (3-(4,5-dimethylthiazol-2-yl)5-(3-carboxymethoxyphenyl)-2-(4-sulfophenyl)-2H-tetrazolium) hydrolysis using a kit from Promega (Promega Corporation, Madison, WI, USA). Assays were made in triplicate. For the growth assays, cells were grown in culture media and counted every week. Growth was represented as cumulative growth of cells infected with Lenti-CMVGSE24.2-eGFP or LV-CMV-GSE4-eGFP in relation of growth of Lenti-CMV-eGFP-infected cells. Growth was monitored until 60 days after infection.

\section{Statistical analysis}

For the statistical analysis of the results, the mean was taken as the measurement of the main tendency, whereas standard deviation was taken as the dispersion measurement. Student's $t$-test was performed. The significance has been considered at $* p<0.05$. $* * p<0.01$ and $* * * p<0.001$. GraphPad Software v5.0 was used for statistical analysis and graphic representations.

Acknowledgements RP laboratory is funded by grant P14-01495 and P17-01401 (Fondo de Investigaciones Sanitarias, Instituto de Salud Carlos III, Spain supported by FEDER funds) and CIBER 576/805_ER16PE06P2016 supported by FEDER funds. GG grant "Ministerio de Economía, Comercio y Competitividad y Fondo Europeo de Desarrollo Regional (FEDER)" (SAF2015-68073-R). CM-G is granted by the CIBERER. Work in FC-L laboratory is funded with grants from the Spanish Government (SAF2014-55532-R, Ministerio de Economía, Industria y Competitividad), the regional Andalusian Government (CVI-7948), the Fundación Ramón Areces (XVII Convocatoria Ciencias de la Vida y Materia), the European Research Council (ERC-CoG-2014-647359), and with a Predoctoral Fellowship from AEFAT (Asociación Española Familia Ataxia Telangiectasia) to AS-B. BER OGG1 was kindly provided by Professor Thomas Helleday's Lab, Karolinska Institutet, Sweden. We gratefully acknowledge to Dr. Antonio Cuadrado for the SOD1 promoter, to Monica MartinezBelinchon, and Dolores Morales-Garcia for valuable help in the confocal studies. We also acknowledge Ana Sastre-Perona for useful comments.

\section{Compliance with ethical standards}

Conflict of interest The authors declare that they have no conflict of interest. 
Publisher's note: Springer Nature remains neutral with regard to jurisdictional claims in published maps and institutional affiliations.

\section{References}

1. Lavin MF. Ataxia-telangiectasia: from a rare disorder to a paradigm for cell signalling and cancer. Nat Rev Mol Cell Biol. 2008;9:759-69.

2. McKinnon PJ. ATM and the molecular pathogenesis of ataxia telangiectasia. Annu Rev Pathol. 2012;7:303-21.

3. Shiloh Y, Ziv Y. The ATM protein kinase: regulating the cellular response to genotoxic stress, and more. Nat Rev Mol Cell Biol. 2013;14:197-210.

4. Alvarez-Quilon A, Serrano-Benitez A, Lieberman JA, Quintero C, Sanchez-Gutierrez D, Escudero LM, et al. ATM specifically mediates repair of double-strand breaks with blocked DNA ends. Nat Commun. 2014;5:3347.

5. Andegeko Y, Moyal L, Mittelman L, Tsarfaty I, Shiloh Y, Rotman G. Nuclear retention of ATM at sites of DNA double strand breaks. J Biol Chem. 2001;276:38224-30.

6. Bakkenist CJ, Kastan MB. DNA damage activates ATM through intermolecular autophosphorylation and dimer dissociation. Nature. 2003;421:499-506.

7. Shiloh Y, Kastan MB. ATM: genome stability, neuronal development, and cancer cross paths. Adv Cancer Res. 2001;83: 209-54.

8. Ambrose M, Gatti RA. Pathogenesis of ataxia-telangiectasia: the next generation of ATM functions. Blood. 2013;121:4036-45.

9. Kim J, Wong PK. Targeting p38 mitogen-activated protein kinase signaling restores subventricular zone neural stem cells and corrects neuromotor deficits in Atm knockout mouse. Stem Cells Transl Med. 2012;1:548-56.

10. d'Adda di Fagagna F. Living on a break: cellular senescence as a DNA-damage response. Nat Rev Cancer. 2008;8:512-22.

11. Rodier F, Coppe JP, Patil CK, Hoeijmakers WA, Munoz DP, Raza $\mathrm{SR}$, et al. Persistent DNA damage signalling triggers senescenceassociated inflammatory cytokine secretion. Nat Cell Biol. 2009;11:973-9.

12. Campisi J. Senescent cells, tumor suppression, and organismal aging: good citizens, bad neighbors. Cell. 2005;120:513-22.

13. Machado-Pinilla R, Sanchez-Perez I, Murguia JR, Sastre L, Perona R. A dyskerin motif reactivates telomerase activity in Xlinked dyskeratosis congenita and in telomerase-deficient human cells. Blood. 2008;111:2606-14.

14. Heiss NS, Knight SW, Vulliamy TJ, Klauck SM, Wiemann S, Mason PJ, et al. X-linked dyskeratosis congenita is caused by mutations in a highly conserved gene with putative nucleolar functions. Nat Genet. 1998;19:32-38.

15. Kirwan M, Dokal I. Dyskeratosis congenita: a genetic disorder of many faces. Clin Genet. 2008;73:103-12.

16. Zeng XL, Thumati NR, Fleisig HB, Hukezalie KR, Savage SA, Giri N, et al. The accumulation and not the specific activity of telomerase ribonucleoprotein determines telomere maintenance deficiency in X-linked dyskeratosis congenita. Hum Mol Genet. 2012;21:721-9.

17. Machado-Pinilla R, Carrillo J, Manguan-Garcia C, Sastre L, Mentzer A, Gu BW, et al. Defects in mTR stability and telomerase activity produced by the Dkc1 A353V mutation in dyskeratosis congenita are rescued by a peptide from the dyskerin TruB domain. Clin Transl Oncol. 2012;14:755-63.

18. Manguan-Garcia C, Pintado-Berninches L, Carrillo J, MachadoPinilla R, Sastre L, Perez-Quilis C, et al. Expression of the genetic suppressor element 24.2 (GSE24.2) decreases DNA damage and oxidative stress in X-linked dyskeratosis congenita cells. PLoS ONE. 2014;9:e101424.
19. Iarriccio L, Manguan-Garcia C, Pintado-Berninches L, Mancheno JM, Molina A, Perona R, et al. GSE4, a small dyskerin- and GSE24.2-related peptide, induces telomerase activity, cell proliferation and reduces DNA damage, oxidative stress and cell senescence in dyskerin mutant cells. PLoS One. 2015;10: e0142980.

20. Egusquiaguirre SP, Manguán-García C, Pintado-Berninches L, Iarriccio L, Carbajo D, Albericio F, et al. Development of surface modified biodegradable polymeric nanoparticles to deliver GSE24.2 peptide to cells: a promising approach for the treatment of defective telomerase disorders. Eur J Pharm Biopharm. 2015; 91:91-102.

21. Nitiss JL. Targeting DNA topoisomerase II in cancer chemotherapy. Nat Rev Cancer. 2009;9:338-50.

22. Li T, Zhou ZW, Ju Z, Wang ZQ. DNA damage response in hematopoietic stem cell ageing. Genom Proteom Bioinforma. 2016;14:147-54.

23. Mendelson A, Frenette PS. Hematopoietic stem cell niche maintenance during homeostasis and regeneration. Nat Med. 2015; 20:833-46.

24. Usatyuk PV, Vepa S, Watkins T, He D, Parinandi NL, Natarajan $\mathrm{V}$. Redox regulation of reactive oxygen species-induced p38 MAP kinase activation and barrier dysfunction in lung microvascular endothelial cells. Antioxid Redox Signal. 2003;5:723-30.

25. Kim J, Wong PK. Loss of ATM impairs proliferation of neural stem cells through oxidative stress-mediated p38 MAPK signaling. Stem Cells. 2009;27:1987-98.

26. Pandita TK. ATM function and telomere stability. Oncogene. 2002;21:611-8.

27. Smilenov LB, Mellado W, Rao PH, Sawant SG, Umbricht CB, Sukumar S, et al. Molecular cloning and chromosomal localization of Chinese hamster telomeric protein chTRF1. Its potential role in chromosomal instability. Oncogene. 1998;17:2137-42.

28. Cawthon RM. Telomere measurement by quantitative PCR. Nucleic Acids Res. 2002;30:e47.

29. Ahmed S, Alpi A, Hengartner MO, Gartner A. C. elegans RAD-5/ CLK-2 defines a new DNA damage checkpoint protein. Curr Biol. 2001;11:1934-44.

30. von Zglinicki T. Oxidative stress shortens telomeres. Trends Biochem Sci. 2002;27:339-44.

31. Oikawa S, Kawanishi S. Site-specific DNA damage at GGG sequence by oxidative stress may accelerate telomere shortening. FEBS Lett. 1999;453:365-8.

32. O'Callaghan N, Baack N, Sharif R, Fenech M. A qPCR-based assay to quantify oxidized guanine and other FPG-sensitive base lesions within telomeric DNA. Biotechniques. 2011;51:403-11.

33. Radicella JP, Dherin C, Desmaze C, Fox MS, Boiteux S. Cloning and characterization of hOGG1, a human homolog of the OGG1 gene of Saccharomyces cerevisiae. Proc Natl Acad Sci USA. 1997;94:8010-5

34. Rothblum-Oviatt C, Wright J, Lefton-Greif MA, McGrathMorrow SA, Crawford TO, Lederman HM. Ataxia telangiectasia: a review. Orphanet J Rare Dis. 2016;11:159.

35. Uttara B, Singh AV, Zamboni P, Mahajan RT. Oxidative stress and neurodegenerative diseases: a review of upstream and downstream antioxidant therapeutic options. Curr Neuropharmacol. 2009;7:65-74.

36. Kamsler A, Daily D, Hochman A, Stern N, Shiloh Y, Rotman G, et al. Increased oxidative stress in ataxia telangiectasia evidenced by alterations in redox state of brains from Atm-deficient mice. Cancer Res. 2001;61:1849-54.

37. Reichenbach J, Schubert R, Schindler D, Muller K, Bohles H, Zielen S. Elevated oxidative stress in patients with ataxia telangiectasia. Antioxid Redox Signal. 2002;4:465-9.

38. Shackelford RE, Innes CL, Sieber SO, Heinloth AN, Leadon SA, Paules RS. The Ataxia telangiectasia gene product is required for 
oxidative stress-induced G1 and G2 checkpoint function in human fibroblasts. J Biol Chem. 2001;276:21951-9.

39. Lee JH, Kim KH, Morio T, Kim H. Ataxia-telangiectasia-mutateddependent activation of $\mathrm{Ku}$ in human fibroblasts exposed to hydrogen peroxide. Ann N Y Acad Sci. 2006;1091:76-82.

40. Takao N, Li Y, Yamamoto K. Protective roles for ATM in cellular response to oxidative stress. FEBS Lett. 2000;472:133-6.

41. Cooke MS, Evans MD, Dizdaroglu M, Lunec J. Oxidative DNA damage: mechanisms, mutation, and disease. FASEB J. 2003; 17:1195-214.

42. Berquist BR, Wilson DM 3rd. Pathways for repairing and tolerating the spectrum of oxidative DNA lesions. Cancer Lett. 2012; 327:61-72.

43. Erker L, Schubert R, Elchuri S, Huang TT, Tarin D, Mueller K, et al. Free Radic Biol Med. 2006;41:590-600.

44. Coppe JP, Desprez PY, Krtolica A, Campisi J. The senescenceassociated secretory phenotype: the dark side of tumor suppression. Annu Rev Pathol. 2010;5:99-118.

45. Pietzner J, Merscher BM, Baer PC, Duecker RP, Eickmeier O, Fussbroich D, et al. Low-dose irradiation prior to bone marrow transplantation results in ATM activation and increased lethality in Atm-deficient mice. Bone Marrow Transplant. 2016;51:619.
46. Opresko PL, Shay JW. Telomere-associated aging disorders. Ageing Res Rev. 2017;33:52-66.

47. Pandita TK, Hittelman WN. Increased initial levels of chromosome damage and heterogeneous chromosome repair in ataxia telangiectasia heterozygote cells. Mutat Res. 1994;310:1-13.

48. Gomez-Herreros F, Romero-Granados R, Zeng Z, Alvarez-Quilon A, Quintero C, Ju L, et al. TDP2-dependent non-homologous endjoining protects against topoisomerase II-induced DNA breaks and genome instability in cells and in vivo. PLoS Genet. 2013;9: e1003226.

49. Sanchez-Perez I, Murguia JR, Perona R. Cisplatin induces a persistent activation of JNK that is related to cell death. Oncogene. 1998; 16:533-40.

50. Carrillo J, Martinez P, Solera J, Moratilla C, Gonzalez A, Manguan-Garcia C, et al. High resolution melting analysis for the identification of novel mutations in DKC1 and TERT genes in patients with dyskeratosis congenita. Blood Cells Mol Dis. 2012; 49:140-6.

51. Rojo AI, Salinas M, Martin D, Perona R, Cuadrado A. Regulation of $\mathrm{Cu} / \mathrm{Zn}$-superoxide dismutase expression via the phosphatidylinositol 3 kinase/Akt pathway and nuclear factor-KB. J Neurosci. 2004;24:7324-34. 